\title{
Carbon Nanotubes: Smart Drug/Gene Delivery Carriers
}

This article was published in the following Dove Press journal:

International Journal of Nanomedicine

Hossein Zare, (D) I,2 Sepideh Ahmadi, ${ }^{3,4}$ Amir Ghasemi, ${ }^{5}$

Mohammad Ghanbari, ${ }^{6}$

Navid Rabiee, (iD) ${ }^{7}$

Mojtaba Bagherzadeh, ${ }^{7}$

Mahdi Karimi, (iD) ${ }^{8-11}$

Thomas J Webster, (ID) ${ }^{12}$

Michael R Hamblin, (iD ${ }^{13}$

Ebrahim Mostafavi (iD) 12,14,15

'Advances Nanobiotechnology and Nanomedicine Research Group (ANNRG), Iran University of

Medical Sciences, Tehran, Iran; ${ }^{2}$ Biomaterials Group, Materials Science and Engineering Department, Iran University of Science and Technology, Tehran, Iran;

${ }^{3}$ Student Research Committee, Department of

Medical Biotechnology, School of Advanced

Technologies in Medicine, Shahid Beheshti

University of Medical Sciences, Tehran, Iran;

${ }^{4}$ Cellular and Molecular Biology Research Center,

Shahid Beheshti University of Medical Sciences,

Tehran, Iran; ${ }^{5}$ Department of Engineering, Durham

University, Durham, DHI 3LE, United Kingdom;

${ }^{6}$ School of Metallurgy and Materials Engineering,

University of Tehran, Tehran, Iran; ${ }^{7}$ Department of

Chemistry, Sharif University of Technology, Tehran, Iran; ${ }^{8}$ Cellular and Molecular Research Center, Iran University of Medical Sciences, Tehran, Iran;

'Department of Medical Nanotechnology, Faculty

of Advanced Technologies in Medicine, Iran

University of Medical Sciences, Tehran, Iran;

${ }^{10}$ Oncopathology Research Center, Iran University

of Medical Sciences, Tehran, Iran; " Research

Center for Science and Technology in Medicine,

Tehran University of Medical Sciences, Tehran, MA,

Iran; ${ }^{12}$ Applied Biotechnology Research Centre,

Tehran Medical Science, Islamic Azad University,

Tehran, MA, Iran; ${ }^{13}$ Laser Research Centre, Faculty

of Health Science, University of Johannesburg,

Doornfontein, 2028, South Africa; ${ }^{14}$ Stanford

Cardiovascular Institute, Stanford, CA, USA;

${ }^{15}$ Department of Medicine, Stanford University

School of Medicine, Stanford, CA, USA

Correspondence: Ebrahim Mostafavi

Stanford Cardiovascular Institute, Stanford

University School of Medicine, Biomedical

Innovation Building, 240 Pasteur Dr, Palo Alto,

CA, 94304, USA

Email ebimsv@stanford.edu

Michael R Hamblin

Laser Research Centre, Faculty of Health

Science, University of Johannesburg,

Doornfontein, 2028, South Africa

Email hamblin.lab@gmail.com

\begin{abstract}
The unique properties of carbon nanotubes (CNTs) (such as their high surface to volume ratios, enhanced conductivity and strength, biocompatibility, ease of functionalization, optical properties, etc.) have led to their consideration to serve as novel drug and gene delivery carriers. CNTs are effectively taken up by many different cell types through several mechanisms. CNTs have acted as carriers of anticancer molecules (including docetaxel (DTX), doxorubicin (DOX), methotrexate (MTX), paclitaxel (PTX), and gemcitabine (GEM)), anti-inflammatory drugs, osteogenic dexamethasone (DEX) steroids, etc. In addition, the unique optical properties of CNTs have led to their use in a number of platforms for improved photo-therapy. Further, the easy surface functionalization of CNTs has prompted their use to deliver different genes, such as plasmid DNA (PDNA), micro-RNA (miRNA), and small interfering RNA (siRNA) as gene delivery vectors for various diseases such as cancers. However, despite all of these promises, the most important continuous concerns raised by scientists reside in CNT nanotoxicology and the environmental effects of CNTs, mostly because of their non-biodegradable state. Despite a lack of widespread FDA approval, CNTs have been studied for decades and plenty of in vivo and in vitro reports have been published, which are reviewed here. Lastly, this review covers the future research necessary for the field of CNT medicine to grow even further.
\end{abstract}

Keywords: drug delivery, gene delivery, carbon nanotube, precision medicine

\section{Introduction}

In recent decades, research in the field of biotechnology has focused on nanotechnology and nanomaterials. ${ }^{1,2}$ Nanomaterials are especially well suited for medical applications because of their unique properties including facile synthesis, controllable size, tunable surface chemistry, large surface-to-volume ratios and significant biocompatibility; all considered as promising for almost all aspects of biotechnology to overcome the many limitations in existing conventional materials. ${ }^{3}$ For instance, pioneering research conducted by Higuchi et al on albumin nanoparticles indicated that nanomedicine may be an effective treatment for cancer due to their ability to avoid immune system clearance enhancing tumor and cancer cell targeting. ${ }^{4}$ Besides, nanomaterials as coatings on coronary artery stents and drug delivery systems for treating coronary artery disease have been reviewed. ${ }^{5}$ Indeed, using nanoparticles in a large range of biomedical applications promises safer (for example, through targeted nanomedicines by reducing the amount of drug delivered) and more effective solutions for a number of diverse issues. ${ }^{6}$ In recent years, the applications of nanomaterials including liposomes, noisomes, ceramic nanoparticles, carbon-based nanomaterials, titanium dioxide nanoparticles, iron oxide 
nanoparticles, polymer nanoparticles, dendrimers, metal nanoparticles, magnetic nanoparticles, silica nanoparticles, etc. in the biological and medical fields have exploded. ${ }^{7-13}$ Also, smart stimulus-responsive drug/gene delivery systems based on the various subclasses of nanomaterials have been considered in recent decades. These systems are responsive against triggers such as $\mathrm{pH}$, redox potential changes, enzymatic activation, thermal gradients, magnetic fields, light, and ultrasound, or a combination of two or more of the above stimulus. ${ }^{14}$

In particular, one nanomaterial, carbon nanotubes (CNTs), has attracted incredible interest in the biomedical field due both to their promising properties (such as high surface area, needle-like structure, considerable strength, flexible interaction with cargo, high drug loading capacity, outstanding optical and electrical features, high stability, biocompatibility, and ability to release therapeutic agents at targeted sites) and negative properties (most notably, lack of biodegradability and toxicity). ${ }^{15-21}$ However, despite some negative attributes of CNTs, they continue to show exemplary functions in medicine, specifically in drug delivery systems, ${ }^{22-25}$ gene delivery and gene therapy, ${ }^{26-31}$ bioimaging, ${ }^{32,33}$ diagnostic applications, $^{18,20}$ biosensors, ${ }^{20,34}$ and vaccine delivery ${ }^{35}$ to just name a few. Table 1 shows some of the attractive features of CNTs in various biomedical applications.

But, in spite of the fact that CNTs show desirable biological properties in the body, there are many concerns about their biosafety, from both a manufacturing and medical application point of view. Accurate toxicity studies are therefore essential to fully evaluate the in vivo impact of CNTs before widespread commercial biomedical applications. As will be discussed, the CNT field has been plagued with inaccurate and incomplete toxicity studies ranging from using animal models that do not mimic real CNT exposure routes to studies that do not even fully characterize the impurities, chemistry, charge, and dimensions of the studied CNTs. ${ }^{36}$

CNTs primarily comprise two nanomaterial classes, including single-wall carbon nanotubes (SWCNTs), a single layer of graphene sheets rolled seamlessly as a cylindrical tube, and multiwalled carbon nanotubes (MWCNTs), multi-layer of graphene sheets wrapped on each other in a cylindrical shape. Besides, there are three main ways to manufacture CNTs, including arc discharge, chemical vapor deposition (CVD), and laser ablation, which were discussed in more detail previously. ${ }^{37}$

This review will summarize promising and not-sopromising studies on work regarding the numerous biomedical applications of CNTs. A wide range of research studies, especially from the years 2016-2019, are discussed with critical insight into what such studies actually showed. We review the cellular uptake of CNTs, CNTs in drug delivery, and CNTs in gene delivery. At the end of this work, we also deliberate on concerns raised over the

Table I Different Medical Applications of CNTs

\begin{tabular}{|c|c|c|}
\hline Application & Description & Ref. \\
\hline \multicolumn{3}{|c|}{ Diagnosis and Imaging } \\
\hline Bio-sensing & $\begin{array}{l}\text { CNTs show special optical, mechanical, and electronic properties that make them attractive candidate materials } \\
\text { for the manufacture of optical and electrochemical biosensors }\end{array}$ & {$[141]$} \\
\hline Bio-imaging & Features such as high photostability and absence of quenching, make CNTs suitable for bio-imaging applications & {$[15 \mid]$} \\
\hline \multicolumn{3}{|c|}{ Therapy Applications } \\
\hline $\begin{array}{l}\text { Photo-Thermal } \\
\text { Therapy }\end{array}$ & The ability of CNTs to convert near infrared radiation (NIR) into heat is well known & [152] \\
\hline $\begin{array}{l}\text { Tissue } \\
\text { Engineering }\end{array}$ & $\begin{array}{l}\text { CNTs are good materials for tissue engineering due to their biocompatibility, rigidity, mimicking of natural tissue } \\
\text { nanofibers, stimulating the adhesion and proliferation of cells and ability to form strong } 3 \mathrm{D} \text { architectures }\end{array}$ & [153] \\
\hline $\begin{array}{l}\text { Drug/gene } \\
\text { Delivery }\end{array}$ & $\begin{array}{l}\text { CNTs have been considered as carriers for drug/gene delivery due to their high surface area, multifunctional } \\
\text { surface chemistry, lack of immunogenicity and unique needle-like shapes with an ability to easily penetrate cell } \\
\text { membranes }\end{array}$ & {$[75,154$} \\
\hline $\begin{array}{l}\text { Lab-on-a-chip } \\
\text { devices }\end{array}$ & $\begin{array}{l}\text { Lab-on-a-chip (LOC) devices are miniaturized systems in which tiny volumes of fluids flowing in various channels } \\
\text { are designed for purposes such as drug screening, cell growth, and disease models. In this regard, CNTs have been } \\
\text { used as membrane channels, sensors and channel walls in LOC devices. }\end{array}$ & {$[155]$} \\
\hline
\end{tabular}


toxicology of CNTs and provide thoughts on what the field needs for CNT use in medicine to grow.

\section{Cellular Uptake of CNTs}

The remarkable features of CNTs allow them to be easily taken up by many different types of cells. For example, the needle-like shape enables CNTs to efficiently penetrate cell membranes, which can be good or bad depending on the intended medical application. Hence, CNT uptake properties make them suitable for numerous biomedical applications, notably drug and gene delivery. ${ }^{38,39}$ Despite a wide range of studies on cellular uptake, there are still many open questions about uptake mechanisms and, hence, cellular pathways initiated through the use of CNTs in drug or gene delivery systems. ${ }^{18}$ Of course, it is not just the manner in which CNTs are taken up by cells, but also how many and will they be able to deliver a drug viably to a cell; ${ }^{40}$ hence, the internalization of CNTs and their cargo needs to be carefully studied. As will be described next, a comprehensive review of articles shows that there is no single mechanism for cellular uptake of CNTs, and several (not one) pathways have been elucidated dependent on properties of the CNTs. ${ }^{41}$

Specifically, several mechanisms for the internalization of CNTs have been proposed including: i) direct penetration through the cell membrane or ii) passive uptake and endocytosis mechanisms or active uptake. These mechanisms are also known as independent energy and dependent energy pathways, respectively. ${ }^{42,43}$ Table 2 describes the current literature summarizing CNT entry into various cells, with a focus on dimension, cell type and CNT surface functionalization.

CNT cellular internationalization can occur through a passive pathway or needle mechanism diffusing across the cellular membrane lipid bilayer. A high respect ratio and needle-like structure helps CNTs overcome such barriers. ${ }^{20}$ Another CNT internalization pathway includes endocytosis which can be broken into five categories: ${ }^{44}$ phagocytosis, pinocytosis (mainly micropinocytosis), clathrin-mediated endocytosis or receptor-mediated endocytosis, caveolinmediated endocytosis, and clathrin/caveolae independent. Phagocytosis is an endocytic pathway through which large particles $(\sim 1 \mu \mathrm{m})$ are taken up by cells. For example, phagocytosis is predominant in macrophages, neutrophils, and monocytes. ${ }^{1,15}$ Receptor-mediated endocytosis is the main pathway for cellular uptake involving the formation of clathrin-coated endocytic vesicles. ${ }^{1}$ Caveolae invaginations include nanomaterials about $60 \mathrm{~nm}$ in size. They are rich in proteins such as cholesterol and sphingolipids. Caveolinmediated endocytosis is used for vesicular trafficking as well as bacteria and virus uptake. ${ }^{45}$ The results from various researchers showed that cells may internalize CNTs up to $100 \mathrm{~nm}$ in size by caveolin- and clathrin-mediated endocytosis; however, larger-sized CNTs of more than $300 \mathrm{~nm}$ are taken up through macropinocytosis mechanisms. ${ }^{7,20}$ In addition to the advantages of CNTs and their drug cargo entering cells, each mechanism has its drawbacks that need to be carefully considered (Table 3).

Cellular uptake and the above-mentioned mechanisms are affected by different CNT material properties such as dimension, surface functionalization, functional group chemistry, surface charge, degree of aggregation and agglomeration, CNT type (multi-walled CNTs (MWCNTs) versus single-walled CNTs (SWCNTs)), and cell types, which are briefly discussed in the following paragraphs. ${ }^{43,44,46,47}$

\section{Functionalization}

The main purpose of CNT functionalization is not only to improve the physical properties of CNTs (such as solubility and dispersity) but also to boost the bio-performance of CNTs. Poor dispersity and significant aggregation of CNTs may make them more cytotoxic in the body. ${ }^{48}$ Hence, surface functionalization enables a proper way to reduce the cytotoxicity of CNTs through effective cellular uptake processes. ${ }^{49}$ In addition, functionalization of CNTs directly affects cellular uptake quality and the cellular internalization mechanisms mentioned above. In Table 4, functionalized CNTs and their effect on solubility, toxicity, effective cellular internalization mechanisms, etc. are summarized with a more in-depth discussion provided below.

Part of the functionalized CNTs can predominantly cross cellular membranes by energy-dependent pathways, while others are independent of energy. ${ }^{43,46}$ Experiments on phagocytic RAW 264.7 murine macrophages and A459 human lung carcinoma cells as non-phagocytic cells treated with various inhibitors indicated that about $30-50 \%$ of f-MWCNTs were internalized into both cell lines through an energy-independent mechanism, while another large part of f-mwCNTs were internalized into cells through macropinocytosis and clathrin and caveolae-mediated endocytosis pathways as energy-dependent mechanisms. $^{50}$ Research studies have extensively 
Table 2 Summary of Articles on CNT Cellular Internalization Mechanisms

\begin{tabular}{|c|c|c|c|c|c|}
\hline $\begin{array}{l}\text { Types of Carbon } \\
\text { Nanotubes }\end{array}$ & $\begin{array}{c}\text { Length (L)/ } \\
\text { Diameter (D) }\end{array}$ & $\begin{array}{l}\text { Surface- } \\
\text { Modified } \\
\text { Complex }\end{array}$ & Cell Types & Mechanisms & Ref. \\
\hline SWCNTs & $\mathrm{L}:>\mathrm{I} \mu \mathrm{m}$ & $\begin{array}{l}\text { Pluronic- FI08: } \\
\text { CNT }\end{array}$ & Macrophage cells & Phagocytosis & [156] \\
\hline $\begin{array}{l}\text { SWCNTs } \\
\text { MWCNTs }\end{array}$ & $30-400 \mathrm{~nm}$ & - & $\begin{array}{l}\text { Murine macrophage } \\
\text { RAW264.7 cells }\end{array}$ & Phagocytosis & [62] \\
\hline MWCNT & L: $453.5 \pm 6.2$ & C6-CNTPC & A549 cells & Phagocytosis & {$[20]$} \\
\hline SWCNTS & L:195-630 nm & - & Murine macrophage cells & Macropinocytosis & [60] \\
\hline MWCNTs & $\mathrm{L}:>300 \mathrm{~nm}$ & $\mathrm{P}(4 \mathrm{VP})-\mathrm{MWCNTs}$ & TTI cells & Macropinocytosis & [7] \\
\hline SWCNTs & $\mathrm{L}:<500 \mathrm{~nm} / \mathrm{D}: \mathrm{I}-2 \mathrm{~nm}$ & AO-SWCNTs & Hela cells & Clathrin-mediated endocytosis & [157] \\
\hline MWCNTs & $\mathrm{L}: 10 \mu \mathrm{m} / \mathrm{D}: 60 \mathrm{~nm}$ & - & BEAS-2B cells, HBEpCs & $\begin{array}{l}\text { Clathrin- and caveolae-mediated } \\
\text { endocytosis }\end{array}$ & [158] \\
\hline SWNTs & $\mathrm{L}: 0.05-0.2 \mu \mathrm{m} /<\mathrm{I} \mu \mathrm{m}$ & $\begin{array}{l}\text { SWNT-DNA, } \\
\text { SWNT- proteins }\end{array}$ & HeLa cell & Clathrin-dependent endocytosis & [159] \\
\hline MWCNTs & $\mathrm{D}: \sim 200 \mathrm{~nm}$ & $\begin{array}{l}\text { Oxidized - } \\
\text { MWCNTs }\end{array}$ & Caco- 2 cell & Clathrin-dependent endocytosis & [160] \\
\hline CNTs & L: $250-400 \mathrm{~nm}$ & $\begin{array}{c}\text { PEG-CNT- } \\
\text { ABT737 nanodrug }\end{array}$ & $\begin{array}{l}\text { A549 non-small cell lung } \\
\text { cancer cells }\end{array}$ & Clathrin-mediated endocytosis & [87] \\
\hline SWNTs & $\begin{array}{l}\mathrm{L}: 100-200 \mathrm{~nm} / \mathrm{D}: \mathrm{I}-3 \\
\mathrm{~nm}\end{array}$ & FA-SWNTs & HepG2 cells & $\begin{array}{l}\text { Folate receptor mediated } \\
\text { endocytosis }\end{array}$ & [161] \\
\hline SWNTs & $\begin{array}{c}\mathrm{L}: 50-100 \mathrm{~nm} / \mathrm{D}: \mathrm{I}-3 \\
\mathrm{~nm}\end{array}$ & FA- SWNTs & HepG2 cells & $\begin{array}{c}\text { Folate receptor mediated } \\
\text { endocytosis }\end{array}$ & [162] \\
\hline MWCNTs & $\begin{array}{c}\mathrm{L}: 3 \mathrm{Im} \text { to } 10 \mathrm{Im} / \mathrm{D}: 50 \\
\mathrm{~nm}-300 \mathrm{~nm}\end{array}$ & - & $\begin{array}{l}\text { Human neonatal epidermal } \\
\text { keratinocytes (HEK) }\end{array}$ & $\begin{array}{l}\text { Lectin receptor mediated } \\
\text { endocytic pathway }\end{array}$ & [163] \\
\hline SWCNTs & $\begin{array}{l}\text { L: } 50-200 \mathrm{~nm} / \mathrm{D}: \mathrm{I}-3 \\
\mathrm{~nm}\end{array}$ & FA-SWCNTs & HepG2 cells & $\begin{array}{l}\text { Passive diffusion for } 50 \mathrm{~nm} \text { or less } \\
\text { SWNTs } \\
\text { Clathrin-mediated endocytosis for } \\
\quad 100-200 \mathrm{~nm} \text { SWNTs }\end{array}$ & [164] \\
\hline MWCNTs & D: $20-30 \mathrm{~nm}$ & FITC- MWCNTs & Plant cells & Passive diffusion & [165] \\
\hline
\end{tabular}

Abbreviations: HBEPCs, human bronchial epithelial cells; FA, folate acid; C6-CNTPC, coumarin-6 loaded TPGS conjugated MWCNT.

confirmed that surface modification of CNTs can facilitate select cellular uptake ${ }^{23,26,51}$ as described next.

CNT functionalization is generally divided into two categories: covalent and non-covalent. Singh et $\mathrm{al}^{20}$ in their research reported that coumarin-6 loaded d-alphatocopheryl polyethylene glycol 1000 succinate (TPGS) conjugated multi-walled carbon nanotubes (C6-CNTPC) and coumarin-6 loaded carboxylated MWCNT C6-CNA had higher uptake rates compared to free c6 in A549 cells after $24 \mathrm{~h}$. This TPGS conjugated MWCNT showed a higher percentage of apoptotic cell death, higher cytotoxicity, higher efficiency treatment and safety than non-coated CNTs and docetaxel (DTX). They also showed that C6-CAN followed passive diffusion mechanisms to cross into cells, while C6-CNTPC was preferentially taken up via phagocytosis pathways. In fact, the anti-cancer activity of DTX increased due to the phagocytosis mechanism used for C6-CNTPC; thus, providing a critical design parameter in promoting phagocytosis of drug-loaded CNTs for treating cancer.

In addition to being covalent or non-covalent functionalized, CNTs can be functionalized by different 
Table 3 Advantages and Disadvantages of Various CNT Cellular Internalization Mechanisms

\begin{tabular}{|c|c|c|c|}
\hline Mechanism & Positive Characteristics & Negative Characteristics & Ref. \\
\hline Passive diffusion & $\begin{array}{l}\text { - Rapid diffusion of CNTs across the cell lipid membrane } \\
\text { in a non-invasive manner }\end{array}$ & - Non-specific & [20] \\
\hline Phagocytosis & $\begin{array}{l}\text { - Ability to uptake large particles }(\sim \mathrm{I} \mu \mathrm{m}) \\
\text { - Specific cell-type targeting }\end{array}$ & $\begin{array}{l}\text { - Need a coating on CNTs to enhance recogni- } \\
\text { tion and uptake by phagocytes } \\
\text { o Degradation of cargo by lysosomes }\end{array}$ & {$[15,166]$} \\
\hline Macropinocytosis & $\begin{array}{l}\text { - Ability to uptake large particles } \\
\text { - Uptake of cargo through large vacuoles }\end{array}$ & - Non-specific & {$[7,167]$} \\
\hline $\begin{array}{l}\text { Clathrin-dependent } \\
\text { endocytosis }\end{array}$ & - Size-dependent regulation of particle internalization & - Degradation of cargo by lysosomes & {$[168]$} \\
\hline $\begin{array}{l}\text { Caveolae-mediated } \\
\text { endocytosis }\end{array}$ & $\begin{array}{l}\text { - Specific receptors } \\
\text { - Bypass the endo-lysosomes } \\
\text { - Enhance the efficiency of transfection }\end{array}$ & - Membrane structure dependent & [169] \\
\hline
\end{tabular}

Table 4 Functionalized CNTs and Their Effect on Solubility, Toxicity, and Effective Cellular Internalization Mechanisms

\begin{tabular}{|c|c|c|c|c|}
\hline & $\begin{array}{l}\text { Functionalized- } \\
\text { CNTs }\end{array}$ & Cell Types & Major Results & Ref. \\
\hline \multirow[t]{2}{*}{ Solubility } & SPAN-MWCNT & - & Weaker $\Pi-\Pi$ bonds between CNTs and SPAN, and high solubility & [170] \\
\hline & PI-PEG-SWCNT & Jurkat cell line & Increase in aqueous solubility by non-covalent functionalization of SWCNTs & [17I] \\
\hline \multirow[t]{3}{*}{$\begin{array}{l}\text { Cellular } \\
\text { uptake }\end{array}$} & MWCNT-FITC & $\begin{array}{l}\text { RAW } 264.7 \text { murine macrophages - } \\
\text { A459 human lung carcinoma cells }\end{array}$ & $\begin{array}{l}\text { Surface modification of CNTs can facilitate effective cellular uptake } \\
\text { The ability of f-CNTs to cross the cell membrane of both cells at a } 30-50 \% \\
\text { internalization rate }\end{array}$ & [50] \\
\hline & $\begin{array}{l}\text { Vitamin E TPGS- } \\
\text { MWCNT (C6- } \\
\text { CNTPC) }\end{array}$ & A549 cells & $\begin{array}{l}\text { Increase in anticancer properties of DTX according to the phagocytosis } \\
\text { mechanism of C6-CNTPC }\end{array}$ & [20] \\
\hline & $\begin{array}{l}\text { PEGylated CNT- } \\
\text { ABT737 }\end{array}$ & $\begin{array}{l}\text { A549 non-small cell lung cancer } \\
\text { cells }\end{array}$ & $\begin{array}{l}\text { Increase mitochondrial targeting with early endosomal escape, increase } \\
\text { accumulation of complex in mitochondria and effective released drug }\end{array}$ & [87] \\
\hline \multirow[t]{7}{*}{ Toxicity } & $\begin{array}{l}\text { SWCNT-PEG- } \\
\text { THFF }\end{array}$ & D54MG-EGFP cells & $\begin{array}{l}\text { This functional group protects D54MG-EGFP cells while the SWCNT backbone is } \\
\text { harmful for these cells }\end{array}$ & [78] \\
\hline & CD-SWCNTs & MCF-7 and HeLa cells & $\begin{array}{l}\text { Decreases the toxicity of CNTs and adverse side effects as a FMN drug delivery } \\
\text { carrier }\end{array}$ & [90] \\
\hline & FA- MWCNTs & HeLa cells & FA- MWCNTs are non-toxic to HeLa cells with cell viabilities more than $90 \%$ & [99] \\
\hline & $\begin{array}{l}\mathrm{CH}-\beta-\mathrm{GP}-\mathrm{CNT} \\
\text { hybrid hydrogels }\end{array}$ & 3T3 cells & $\begin{array}{l}\text { Hydrogels containing CNTs }(0.1 \%) \text { showed no-toxicity in } 3 T 3 \text { cells with high cell } \\
\text { viability }\end{array}$ & [103] \\
\hline & SWCNT-PB (SPB) & 293T and A549 cells & $\begin{array}{l}\text { SPB showed low cytotoxicity to both cell lines and more than an } 80 \% \text { cell viability } \\
\text { at a high concentration of } 50 \mu \mathrm{gL}^{-1}\end{array}$ & {$[121]$} \\
\hline & $\begin{array}{l}\text { SWNT-PEG-PEI- } \\
\text { ASI } 4 \text { II aptamer }\end{array}$ & L929 and AGS cells & This functionalized nanoplex showed low cytotoxicity in cells & [67] \\
\hline & $\begin{array}{l}\text { SWNT-PEI } \\
\text { conjugates }\end{array}$ & N2A murine neuroblastoma cells & $\begin{array}{l}\text { None of the SWNT-PEII I0, and SWNT-PEII I } 0 \text { carriers had major cytotoxicity except } \\
\text { SWNT-acyl-PEII.8 (SI.8), SWNT-acyl-PEIIO (ACI0) and SWNT-acyl-PEI25 (AC25) }\end{array}$ & [127] \\
\hline
\end{tabular}

Abbreviations: PI-PEG, phospholipid-PEG; FA, folic acid; CH, chitosan; $\beta$-GP, $\beta$-glycerophosphate; PB, PEI-betaine; SPAN, sulfonated polyaniline; FMN, formononetin. 
functional groups which can also influence the cellular uptake process. $^{52}$ For example, Chatterjee et al ${ }^{53}$ conducted research on the uptake of functionalized MWCNTs (hydroxylated/carboxylated MWCNTs) by human bronchial epithelial (BEAS-2B) and human hepatoma (HepG2) cells. Clathrin-mediated endocytosis was recognized as the main pathway for carboxylated MWCNT uptake whereas both caveolae- and clathrinmediated endocytosis were found for hydroxylated MWCNT internalization by both types of cells. A higher cytotoxicity of carboxylate in BEAS-2B cells was observed, although hydroxylate in HepG2 cells indicated functionalization dependent cell-type effects. Also, Budhathoki-Uprety et $\mathrm{al}^{34}$ revealed that cellular uptake of amine-CNTs was higher than carboxyl-CNTs and showed a dependency of cellular uptake on the type of functional group for HeLa cells after $24 \mathrm{~h}$.

Some of the studies showed that functionalized CNTs are able to pass or penetrate physical barriers (for example, the Blood-Brain Barrier (BBB)). Kafa et al showed that angiopep-2 (ANG)-functionalized MWNTs were able to cross the $\mathrm{BBB}$ by a co-culture $\mathrm{BBB}$ model containing primary rat astrocytes and primary porcine brain endothelial cells. $f$-MWCNTs were able to pass through the BBB after in vivo injection through the tail vein and showed a higher brain parenchyma accumulation of $f$-MWNTs after the injection. Micropinocytosis seems to be the chief internalization mechanism and transcellular uptake is offered as the primary mechanism in order to cross the $\mathrm{BBB}^{54}$

In an in vivo study by Ren et al, PEGylated oxidized MWNTs (oxMWNT-PEG) functionalized with ANG were applied to deliver Doxorubicin (DOX) to C6 mouse glioma model brains. With improved brain uptake of DoxoxMWNT-PEG modified with ANG, they showed a significant survival of glioma-bearing mice treated with Dox-oxMWNT-PEG-ANG than control groups. The results of this study showed that this carrier could distribute to the brain with high proficiency and O-MWNTsPEG-ANG could increase brain distribution according to the receptor-mediated endocytosis mechanism of ANG interaction with lipoprotein receptor-related protein (LRP) receptors. ${ }^{55}$

In a study, the in vivo administration of functionalized CNTs ( $f$-MWNT) modified with siRNA targeting caspase3 into the brain cortex of a stroke model proved their capability to be internalized in neuronal cells, which is shown with TEM after $48 \mathrm{~h}$ of f-CNT internalization.
$f$-MWNT-siRNA was delivered to the cortex of rats through stereotactic injection. After the siRNA-CNTs were delivered, the anti-caspase-3 siRNA treated rats showed a major reduction in apoptotic cells and decreased neurodegeneration before and after ischemic damage of the rodent motor cortex. ${ }^{56}$

\section{Size}

CNT dimension is clearly one of the most significant parameters which can influence cellular uptake. Previous research illustrates that shorter CNTs result in more efficient cellular uptake. ${ }^{57-59}$ The mechanism via which short CNTs transfer through cell membranes is not unique, but the main one is active endocytosis, especially clathrin-mediated endocytosis. ${ }^{7,60,61}$ Shortening of CNTs, however, increases the chance of passive internalization. ${ }^{15}$ In this regard, Zhang et al studied the effect of dynamic particle size of CNTs on cellular uptake. They compared the uptake of eight types of CNTs, including SWCNTs and MWCNTs, by RAW264.7 macrophages with sizes ranging from 30 to $400 \mathrm{~nm}$. Their results indicated that an increase in dynamic particle size caused CNTs to be taken up by macrophages in larger quantities following an increase in cytotoxicity with the main mechanism of the cellular uptake being energy-dependent phagocytosis. ${ }^{62,63}$

\section{Degree of Agglomeration and Aggregation}

Internalization of CNTs may be affected by the state of their agglomeration and aggregation. Song et $\mathrm{al}^{64}$ reported that larger agglomerates of O-MWCNTs result in higher uptake by human epithelial cervical cancer (HeLa) cells, but did not induce obvious cytotoxicity in these cells when the concentration of O-MWCNTs was less than $150 \mu \mathrm{g} /$ $\mathrm{mL}$ (with a size of 200-700 $\mathrm{nm}$ in length and 10-20 nm in diameter). By increasing the concentration of O-MWCNTs to $150 \mu \mathrm{g} / \mathrm{mL}$, after $24 \mathrm{~h}$, the amount of agglomeration and toxicity increased slightly. They contended that agglomeration helped endocytosis of O-MWCNTs owing to their effective interaction of agglomerates with cells. This highuptake and low-toxicity of CNT agglomerates can facilitate drug/gene delivery through regulating agglomeration of CNTs in some delivery systems. Kuroda et $\mathrm{al}^{65}$ conducted research that proved that aggregated CNTs possessed enhanced uptake in RAW264 cells. Their results 
suggested that uptake mechanisms are influenced by the state of aggregation.

\section{Surface Charge}

Surface charge can alter electrostatic interactions and dispersity of CNTs. ${ }^{66,67}$ Hence, surface charge can influence cellular uptake and consequently other biological performance. ${ }^{68,69}$ Budhathoki-Uprety et $\mathrm{al}^{34}$ functionalized SWCNTs by encapsulation in helical polycarbodiimide polymers functionalized with primary amine (amine-CNT) or carboxylic acid (carboxy-CNT) side chains. The amineand carboxy-SWCNT complexes have surface charges of approximately $52.8 \mathrm{mV}$ and $66.8 \mathrm{mV}$, respectively. They showed that cationic nanotubes were efficiently internalized into HeLa cells in comparison with anionic CNTs. However, cellular uptake of the anionic CNTs was influenced by serum proteins in cell culture media which adsorb to the CNTs. It is important to remember that it is the proteins that adsorb to nanomaterials which cells recognize, not the nanomaterial itself; this is the so-called nanomaterial "protein corona" effect. In fact, the protein corona is a layer of proteins adsorbed to a nanomaterial (without protective modifications) when exposed to body fluids. ${ }^{70}$ This provides for incredible leverage in designing CNTs that can either be taken up into cells (and via which mechanisms) or not. Therefore, considering the surface chemistry modulation of CNTs, one can design efficient drug delivery strategies.

However, various toxicity properties of nanomaterials arise from the reactivity of their surface with cellular membranes. The toxicological properties of CNTs are associated with the nonbiodegradability of these nanoparticles. The connecting of blood proteins to CNTs influences cellular pathways and decreases the cytotoxicity that is determined by the existence of specific protein adsorption. $^{71} \mathrm{Ge}$ et al examined the interaction between SWCNTs and human blood proteins on the cytotoxicity of SWCNTs in two cell lines, such as an acute human monocyte leukemia cell line (THP-1) and a human umbilical vein endothelial cell line, showing that the binding of blood proteins on the SWCNT surface enabled changes in their cellular interactions reducing their cytotoxicity. ${ }^{72}$

\section{Cell Type}

Different cellular systems have different rates of cellular uptake and can alter the mechanisms of the uptake process. $^{7,26,39,73} \mathrm{CNT}$ internalization by human lung cancer cells A549, human lung cancer cells Calu-6, human breast cells MCF-7, and mouse macrophage cells J774 have been studied by Summers et $\mathrm{al}^{68}$. They found that CNT uptake was the highest in the J774 cell line. The uptake into A549 cells was $40 \%$ lower than the $\mathrm{J} 774$ cell line which had the greatest uptake among all cells after 24 $\mathrm{h}$ exposure to CNTs. MCF-7 and Calu-6 cells showed no significant difference, but both cell types had $\sim 30 \%$ of the J774 CNT content. Furthermore, macrophages took up SWCNTs in larger quantities compared to fibroblasts. Macrophages took up large particles (with diameters $>500 \mathrm{~nm}$ ) through phagocytosis preferentially, however, fibroblasts primarily use endocytosis of particles with diameters $<200 \mathrm{~nm}^{58} \mathrm{~J} 774$ cells are phagocytic cells and have the ability to absorb larger particles and CNT agglomerates. This aggregation of CNTs within phagocytic cells can facilitate the retention of nanoparticles within cells, and it makes these cells suitable carriers of CNTs into tumor cells for cancer therapy.

Various techniques have been adopted to analyze CNTs and their cellular uptake including transmission electron microscopy, fluorescence microscopy, atomic force microscopy, dynamic light scattering, confocal Raman microscopy as well as surface-enhanced Raman scattering and confocal laser scanning microscopy. These techniques utilize some features such as the optical properties of CNTs to characterize and visualize their cellular uptake. ${ }^{1,44,53,63,74}$ It is often said that improvements in microscopy led to the field of nanotechnology, and this could not be more true when understanding CNT cellular internationalization mechanisms.

\section{Drug Delivery}

As stated previously, several mechanisms determine how CNTs enter cells. Their length, degree of aggregation, and surface functionality determine which cellular uptake mechanism occurs. ${ }^{75}$ Despite some concerns about the immune response of the pulmonary system towards pristine CNTs and the change that might occur with CNT exposure in terms of gene expression in normal cells, which will be discussed further in one of the future sections, CNT surface modification and, more specificity, the ability of CNTs to target cells can reasonably satisfy all of these concerns.

Adding surface functionalities on CNTs can enhance cellular uptake through enhanced permeability and retention, the so-called "EPR effect," a mechanism for accumulating nanoparticles in tumors due to their increased blood flow, and specific targeting by a select antigen or 
aptamer. For example, it has been demonstrated that CNT drug delivery systems (DDSs) can carry anti-cancer drugs to fight against malignant melanoma, which usually includes polyethylene glycol (PEG) on the surface of the CNTs. ${ }^{76}$ In fact, it has been reported that even MWCNTs without drug loading with any anti-cancer drugs can inhibit tumor growth. Specifically, a study conducted by Garcia-Hevia et al showed that an injection of $2 \mu \mathrm{g}$ MWCNT in a melanoma tumor, transplanted into the back of a mouse, reduced tumor mass by $27 \%$ compared to untreated mice. ${ }^{77}$ Similarly, SWCNTs functionalized with PEG $(23 \% \mathrm{wt})$ or tetrahydrofurfuryl (THFF)terminated PEG $(21 \% \mathrm{wt})$ was tested against human glioma cells to evaluate their effects on cell adhesion, proliferation, and death rate of D54MG-EGFP cells. The findings demonstrated a $21 \%$ decrease in cell proliferation of D54MG cells near SWCNT-PEG-THFF (compared to the control). In addition, a 35\% increase in cell death rate was observed for the SWCNT-PEG-THFF group compared to the SWCNT-PEG group after two days. The study concluded that the functional groups possessed a protective effect for D54MG-EGFP cells, while the SWCNT backbone was harmful to them. ${ }^{78}$ Despite the assumption that PEG is an innocent agent against immunogenic responses, several research studies including animal studies in mice, ${ }^{79}$ rabbits, ${ }^{80}$ rats and monkeys, ${ }^{81}$ showed that various PEGylated agents could trigger antibody formation against PEG. Furthermore, recent work on PEGylated therapeutics in humans demonstrated even adverse reactions. For instance, PEGinesatide (OMONTYS) was approved by the FDA in 2011 for treating anemic patients who have chronic kidney disease. ${ }^{82}$ However, the drug was reported to show severe hypersensitivity reactions, which were $0.02 \%$ fatal in patients after 30 min of injection; ${ }^{83}$ the drug was banned and withdrawn from the market in $2013{ }^{84}$

Additionally, some researchers are skeptical if this cancer cell inhibitory effect of CNTs can be repeated in 3-D cultures or animals. For example, a study investigated the possibility of using functionalized MWCNTs for photothermal therapy of glioblastoma cells and compared the results of placing MWCNTs near cancer cell lines in 2-D and 3-D cultures. They concluded that functionalized MWCNTs showed an inhibitory effect on a 2-D culture of glioblastoma cells and not for the 3 -D cultures. ${ }^{85}$ This phenomenon is probably related to acid-oxidation and other mechanisms that mitigate acute CNT toxicity in vivo. So, CNT morphology plays a vital role in toxicology investigations related to CNT DDSs. Further, such studies highlight the importance of the assay and experimental system used to test the efficacy, not only for CNTs but also for nanomaterials.

\section{CNTs as Carriers of Anticancer Molecules}

Cao et al used a pH-responsive release of docetaxel (DTX) loaded on arginylglycylaspartic acid (RGD)-chitosan (CS) decorated functionalized SWCNTs. The RGD-CSSWCNT-DTX complex showed a higher drug release of $68 \%$ than the pure drug at $\mathrm{pH} 5.0$ and $49 \%$ at $\mathrm{pH} 7.4{ }^{86}$

In similar work, a group of researchers tested the behavior of PEG-functionalized MWCNTs loaded with ABT737, a nanodrug for treating lung cancer cells, against A549 cells. The cellular uptake was clathrin-dependent, which is a form of endocytosis, and in this way, a strategy was designed for the loaded MWCNTs to enter the cells to guide them into the mitochondria before early endosomal escape occurred. ABT737 can attack the mitochondria of cancer cells to cause apoptosis of the cells. So, this study's main goal was to use $\mathrm{pH}$ as the stimulus to trigger a drugreleasing response. The findings showed $56 \%$ and $32 \%$ apoptosis for cells near $1-5 \mu \mathrm{g} / \mathrm{mL}$ of PEG-MWCNTABT737 (24\% wt loaded with drug) and the free ABT737 nanodrug, respectively, thus demonstrating more significant apoptosis for the MWCNT group. Additionally, normal cell apoptosis was reported to be $3 \%$ and $1.5 \%$, respectively. ${ }^{87}$ The presence of the integrin $\alpha_{V} \beta_{3}$ is attributed to the expression of various human cancer lines. ${ }^{88} \mathrm{In}$ this regard, Koh et al designed a DDS system in which an RGD peptide covalently conjugated on the surface of functionalized CNTs with carboxylic acid (fCNTs), followed by encapsulation of topoisomerase I inhibitor camptothecin (CPT) in the functionalized CNTs, to reach CPT@fCNT-RGD. Treating A375/MCF6 cells with different concentrations of CPT-encapsulated fCNT-RGD, CPTencapsulated fCNTs and fCNT-RGD ranging from 0.1 to $150 \mu \mathrm{g} / \mathrm{mL}$ showed a drop of $67.9 \%, 31.9 \%$ and $28.9 \%$ in cell viability, respectively. ${ }^{89}$

Research on CNTs as an anti-cancer drug carrier has been investigated in many anti-tumor DDSs such as DTX, ABT737, DOX, methotrexate, PTX, gemcitabine (GEM), mangiferin (MF), etc. As another example, it has been shown that carboxylated SWCNTs functionalized with hydroxypropyl- $\beta$-cyclodextrin (HP- $\beta$-CD) are proper carriers for formononetin (FMN) delivery, because the cell 
viability of MCF-7 cells against CD-SWCNTs-FMN was always recorded at lower amounts compared to the cell viability by FMN alone with concentrations ranging from 3 to $100 \mu \mathrm{mol} / \mathrm{L}$ after $48 \mathrm{~h}$. At higher doses (more than 50 $\mu \mathrm{mol} / \mathrm{L})$, the difference between CD-SECNTs-FMN and FMN was more prominent. ${ }^{90}$ Therefore, this study is an example that not only can CNTs improve the efficiency of chemotherapy (through improving the drug delivery capacity to the target) but also these nanoparticles can decrease side effects related to the usage of higher doses of drugs (ie, lower cytotoxicity reported).

Considering that mangiferin (MF) is a phytochemical compound that may positively affect treating such illnesses like diabetes, viral infections and cancers, ${ }^{91}$ a CNTPEG-based system conjugated with MF was assessed in terms of its effectiveness against human brain cancer cells. While the plain MF drug release at $\mathrm{pH} 5.6$ and 7.4 was reported as $74 \%$ and $59 \%$, those values for the conjugated MF on CNT-PEG platform was reduced to $59 \%$ and $50 \%$, respectively. Because the drug release amount was recorded at higher values for a $\mathrm{pH}$ of 5.6 than 7.4, a $\mathrm{pH}$ dependent strategy can target cancerous cells that have an intrinsically acidotic nature. Various concentrations ranging from 1 to $100 \mu \mathrm{M}$ of MF and CNT-PEG-MF were assessed in the vicinity of U-87 cancer cell lines for 48 h. $\mathrm{IC}_{50}$ values for free MF and CNT-PEG-MF were equal to $208.48 \mu \mathrm{M}$ and $162.91 \mu \mathrm{M}$, respectively. The higher cytotoxic effects of CNT-PEG-MF can be attributed to improved cell penetration or cellular uptake of NPs than free MF. The flow cytometric data also showed around $55 \%$ apoptosis for conjugated MF on a CNT-PEG platform versus $21 \%$ for plain MF against the U-87 cells. ${ }^{92}$

In addition, a study supervised by Raza et al compared MWCNT-DTX vs MWCNT-DTX conjugated with piperin. Figure 1 shows a schematic of how DTX was loaded on MWCNTs. Since one of the major problems in working with DTX is its poor bioavailability and aqueous solubility, piperin can increase both of them. In vitro results determined the release profile of DTX for MWCNT-DTX and the conjugate after $24 \mathrm{~h}$. The release for the former combination was $87.5 \%$, but the latter was $63.9 \%$. However, using piperin did not affect the anti-cancer activity of DTX. ${ }^{93}$ Further investigations on SWCNTs loaded with gemcitabine (GEM) and functionalized with PEG showed controversial results. The amount of GEM on the SWCNT and SWCNT-PEG was recorded at $43.14 \%$ and $34.34 \%(\mathrm{w} / \mathrm{w})$, respectively. In vitro findings for 20nM GEM after $48 \mathrm{~h}$ demonstrated the amount of GEM at $19.6 \%$ and $11.1 \%$, respectively, for SWCNT-GEM and SWCNT-PEG-GEM; a higher cytotoxicity was reported against A549 cells compared to the pure GEM at the same concentration. However, an in vivo study proved that SWCNT-PEG-GEM inhibited tumor growth more compared to SWCNT-GEM. Once again, the importance of 3-D investigations and associated factors that are not present in 2-D tests is clear. Opposite findings may be found in vivo and can be attributed to the enhancement of blood circulation time for the functionalized CNTs with PEG as well as a complete immune system response. So, the EPR effect was probably higher for the SWCNT-PEGGEM which contributed to the results. ${ }^{94}$

Doxorubicin (DOX) is widely used as a chemotherapeutic medication, but it has disadvantages, such as reversible side effects, low ability to cross biological barriers, and irreversible toxicity. ${ }^{95} \mathrm{CNTs}$ can be used effectively as a suitable transporter for carrying these drugs and reducing side effects due to their high surface area, thermal and chemical stability, and ability to pass through cell membranes. ${ }^{96}$

Liu et al reported that a DOX-dependent drug is effective for the treatment of breast cancer so, for this purpose, aminofunctionalized single-walled carbon nanotubes $\left(\mathrm{NH}_{2}-\right.$ SWCNTs) were combined with hyaluronic acid (HA) (SWCNTs-DOX-HA) and the in vitro release of DOX at a $\mathrm{pH}$ of 5.5 in the tumor cell environment was found to be faster than when the medication was released in the biological environment. According to the results, tumor cell growth and induction of apoptosis can be reduced using SWCNTsDOX-HA compared to SWCNTs-DOX and a nano-size formulation enhanced the treatment of breast cancer. ${ }^{97} \mathrm{~A}$ recent paper by the same group focused on assessing the SWCNTsDOX-HA DDS on a spheroid (3D) cancer cell line model. Therefore, the SWCNTs-DOX-HA system specifically could bind to the CD44 receptor on MDA-MB-231 cells probably by cellular uptake through receptor-mediated endocytosis. The control cancerous spheroid volume increased to 1.2 times the original size after 5 days of culturing. Similarly, the volume of spheroids treated with free DOX, SWCNTDOX-HA and SWCNT-DOX cut down to almost 21\%, 23\% and $33 \%$, respectively. It suggests that HA improves the cytotoxicity of this DDS compared to SWCNT-DOX alone. $^{98}$

Yan et al, during another study, reported that $\mathrm{pH}-$ responsive-SWCNT-folic acid (FA) conjugates had higher drug loading and encapsulation efficiency (70.4\%) because DOX/MWCNT nanocomplexes demonstrated 


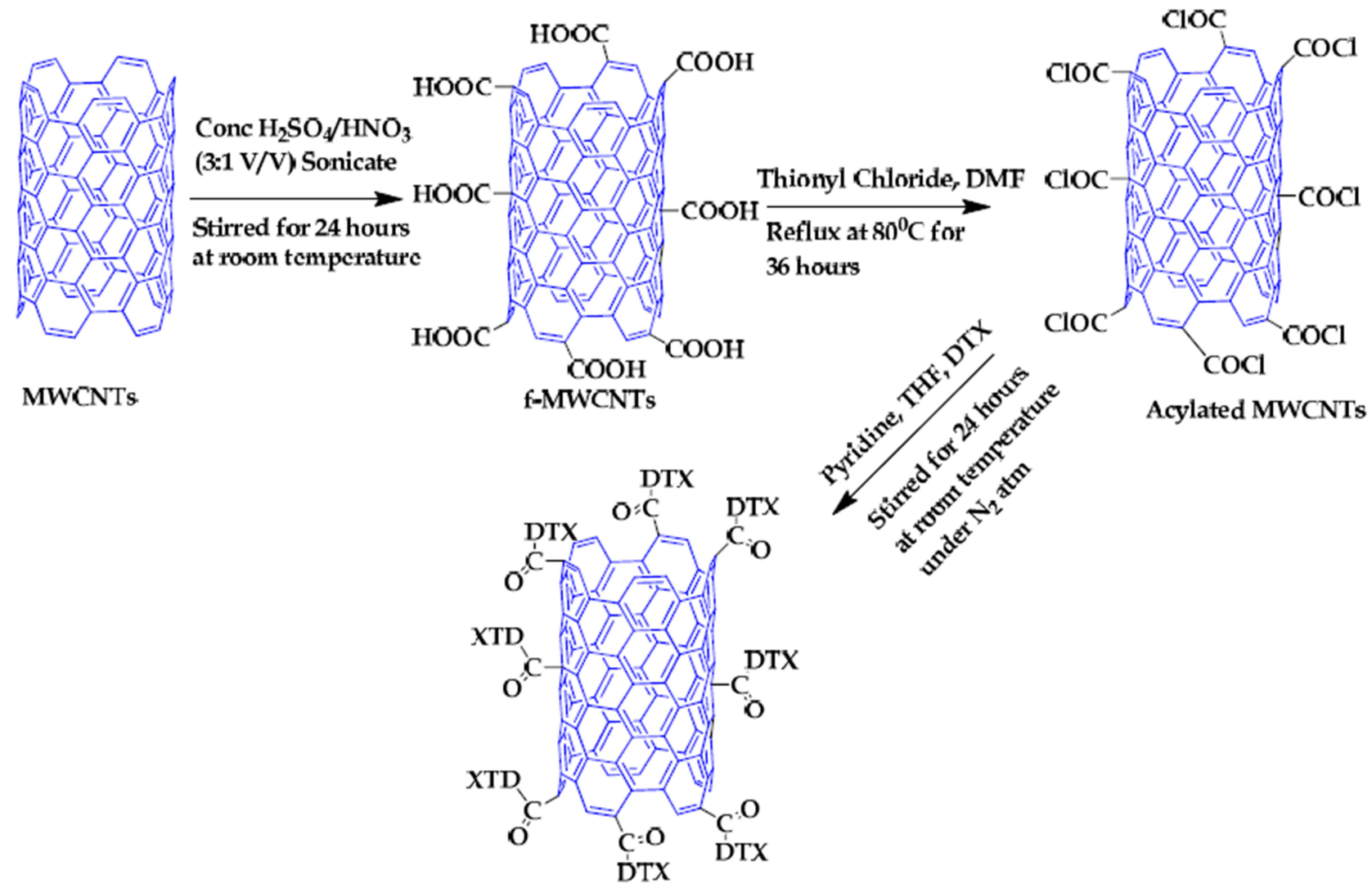

DTX-MWCNTs conjugate

Figure I This scheme shows how DTX was conjugated to MWCNTs.

Notes: Reprinted with permission from Raza K, Kumar D, Kiran C, et al. Conjugation of Docetaxel with Multiwalled Carbon Nanotubes and Codelivery with Piperine: Implications on Pharmacokinetic Profile and Anticancer Activity. Mol Pharm. 2016;13(7):2423-2432. Copyright ๔ 2016 American Chemical Society. ${ }^{93}$

good colloid stability in water, PBS, and cell culture medium as after 2 months, there was no precipitation. They also showed higher anti-tumor effects than free DOX and in vivo studies confirmed that the side effects of DOX (like cardiotoxicity and kidney accumulation) were reduced in the presence of the DOX/MWCNT nanocomplexes. ${ }^{99}$ Another study by Uttekar et al suggested a combination of FA and ethylene diamine (EDA) conjugated on MWCNTs (length $=5-15 \mu \mathrm{m}$, diameter $=10-20 \mathrm{~nm}$ ) as a carrier of DOX for assessing MCF-7 breast cancer cell line viability. In vitro studies showed that after $48 \mathrm{~h}$ at $\mathrm{pH} 5.3$, the rate of drug release from FA-EDA-MWCNTs-DOX was $68.12 \%$ compared to $11.48 \%$ at $\mathrm{pH}$ 7.4. The $\mathrm{pH}$-dependent release profile ascribed to the formation of -CONM amide at a minor $\mathrm{pH}$. Additionally, the FA-EDA-MWCNTs-DOX compound demonstrated $7.58 \%$ cytotoxicity for a $1 \mu \mathrm{g} / \mathrm{mL}$ concentration and $30.31 \%$ cytotoxicity at $100 \mu \mathrm{g} / \mathrm{mL} .^{100}$

PTX is considered an effective anti-cancer drug, but it is insoluble and has a tendency to accumulate. The combination of this drug by covalent and non-covalent bonds with CNTs provides a new platform for cancer therapy. An HA-Chitosan (CHI)-CNT-platform synthesis was carried out by $\mathrm{Yu}$ et al ${ }^{101}$ for $\mathrm{pH}$-dependent controlled

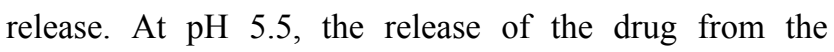
modified SWNTs was more than at physiological $\mathrm{pH}$, which could be due to the dissolution of $\mathrm{CHI}$ in the acidic environment. According to investigations of the therapeutic effect of the drug by A549 cells in vitro, LDH levels as well as reactive oxygen species (ROS) amounts, CNT-CHI -HA toxicity was high but was low in normal cells. Other similar articles are available for pH PTX dependentrelease from CNT-CHI. ${ }^{102}$ Also, co-loading of two DOX and PTX drugs on SWCNT (f-SWCNT) chitosan was carried out by Karnati et al. According to the results, f-SWCNT played an important role in reducing the binding of PTX and DOXs to a nanowire carbon nanofiltration sidewall, increasing sensitivity to $\mathrm{pH}$ due to compacting DOX/PTX-f-SWCNT compared to DOX/PTX-SWCNT and more effective loading of the drugs. f-SWCNT in the 
acidic environment caused a reduction of the $\mathrm{pH}$ and the protonation of chitosan and drugs leading to the controlled release of drugs. ${ }^{102}$

Saeednia et al $^{103}$ prepared a new thermosensitive and injectable carbon nanotube hybrid hydrogel for the controlled release of methotrexate (MTX). Here, the hydrogel was composed of $\beta$ chitosan/ $\beta$-glycerophosphate $(\beta-\mathrm{GP})$ that in the presence of chitosan, played a role in increasing biocompatibility and biodegradability, and $\beta$-GP was effective in facilitating the formation of the thermosensitive hydrogel form. The presence of CNTs in this hydrogel had several significant advantages: 1 . The hydrogel containing CNTs showed no-toxicity towards 3T3 cells. 2. CNTs in the hydrogels were effective at increasing the anti-tumor function of MTX and inhibiting tumor growth. 3. Another advantage was that CNTs played an important role in increasing the rate of swelling and degradation of the hydrogel. MTX was released from the hydrogel-CNT slower and in a more sustained manner due to the addition of CNTs to hydrogels, increasing bonds and producing rigid structures leading to a slower release and more optimal surface. In general, it can be said that CNTs enabled the absorption and entrance of anticancer agents with widely used applications, such as MTX, into cells by reducing systemic toxicity and consequently preventing drug effects on normal cells, as well as a controlled and sustained drug release in tumor cells over a long period of time, increasing the effect of MTX on tumor cells.

GEM has been considered as an anticancer agent for a long time in non-small cell lung and pancreatic cancers. From the clinical perspective, GEM has been limited because of its short plasma half-life (17 min) and rapid metabolism. These limitations lead to higher administration of significant drug doses that can cause severe side effects. PEGylated-SWCNTs-GEM have solved some of the limitations of the use of GEM by providing an ability to penetrate cells, as well as the ability to load the drug $(37.32 \%)$, increasing its circulation time and reducing drug accumulation in reticuloendothelial system (RES) organs, including the liver. First, SWCNTs were functionalized with PEG, and then GEM was loaded at the conjugated surface with a sterile bond. At low $\mathrm{pH}(\mathrm{pH} 5.0$ and 6.8), a faster release of a higher concentration of GEM compared to $\mathrm{pH} 7.4$ was observed by breaking the ester bonds. Therefore, the peptide-PEG-SWCNTs-GEM conjugate cell absorption by $\mathrm{A} 549$ and MIA PaCa-2 cancer cell lines in vitro and in vivo (in the tumor bearing B6 nude mice) showed increased antinuclear activity and decreased tumor cell growth compared to native GEM. ${ }^{94}$

\section{CNTs in Photothermal/Dynamic Therapy}

One of the other recent strategies in oncology is photothermal therapy (PTT). In PTT, photon energy converts rapidly into heat to combat the tumor tissue. CNTs with their excellent optical properties serve as a widespread platform in PTT. ${ }^{104}$

In particular, one study produced a combination of MWCNTs and silver nanorods for PTT since Ag nanorods also have appropriate optical absorbance for PTT and adding MWCNTs will increase cell penetration and dispersibility of Ag nanorods. A layer of PEG coated on the nanoparticles and MWCNTs will further improve their hydrophilicity and use in the body. Studies have shown that after PTT on a murine melanoma cell line B16/F10, histopathology showed cell necrosis of up to $70 \%$ and $60 \%$ for CNTs/Ag and CNTs, respectively. ${ }^{105}$ The same group tested murine melanoma tumor cells with surface modified MWCNTs in which the CNTs were oxidized and then treated with a layer of PEG. This time, cellular necrosis using oxidized MWCNTs coated with a layer of PEG showed more than $90 \%$ necrosis (at $1 \mathrm{mg} / \mathrm{mL}$ of each sample injected into the tumor at a dose of $200 \mu \mathrm{L} / \mathrm{cm}^{3}$ of tumor volume), while the control group only showed $25 \%$ necrosis after receiving an $808 \mathrm{~nm}$ continuous-wave NIR laser at an intensity of $8 \mathrm{~W} / \mathrm{cm}^{2}$ for $10 \mathrm{~min}$ of therapy. ${ }^{106}$ Another group of researchers focused on the effects of using functionalized MWCNTs for PTT against glioblastoma cells. They synthesized MWCNTs functionalized with distearyl phosphatidyl ethanolamine-PEG (DSPEPEG) to stabilize the nanotubes. PEG-DSPE are amphiphilic block copolymers that can use their PEG terminal group to attach to various ligands to prolong the circulation time, better drug bioavailability and decrease undesirable side effects. ${ }^{107}$ TEM analysis showed that the MWCNTs penetrated tissue to a depth of $100 \mu \mathrm{m}$ and most of the nanotubes accumulated in the extracellular space, but some MWCNTs were detected intracellularly. Despite the fact that the NIR laser therapy alone did not affect the spheroid tumor growth rate after 90-120 s, spheroids treated with MWCNTs showed inhibition of glioblastoma tumor growth after receiving NIR irradiation under the same conditions ( 3 to $100 \mu \mathrm{g} / \mathrm{mL}$ ). ${ }^{85}$

Recently, the effects of using SWCNT-glycated chitosan (GC) against 4T1 breast tumor cells while applying irradiation at $1064 \mathrm{~nm}$ was found in a PTT process. GC 
acted in this study as an immunoadjuvant which triggered the host immune cells to respond against the tumor cells. This research also used a $\mathrm{CoMoCAT}^{\circledR}$ technique $^{108}$ to provide SWCNTs with silica-supported bimetallic cobaltmolybdate catalysts. The increasing number of reactive oxygen species (ROS) in cells was determined in order to evaluate the direct effect of the SWCNTS-GC compound on 4T1 tumor cells. Additionally, when the tumor cells were co-incubated with a SWCNT-GC combination for $12 \mathrm{~h}$, then receiving radiation at $1064 \mathrm{~nm}$, the temperature increased in this group was reported to be higher than the control group which only was irradiated at the same wavelength. Interestingly, mice carrying 4T1 breast tumors on their back was treated in two groups of laser treatment only and laser+ SWCNT-CG treatment when the tumor size reached $300 \mathrm{~mm}^{3}$. After 5 days of treatment, the results showed that the lung metastases in the group of laser +SWCNT-GC was lower than the control group. On the other hand, no significant decrease was observed for lung metastases in the laser-only group than the control. ${ }^{109}$

Another group tested SWCNTs as absorbents of NIR light. They synthesized SWCNTs and modified their surface with annexin $\mathrm{V}$ (which is a specific target for phosphatidylserine) on murine bladder tumor cells. An in vivo study showed that after 116 days, there was a 50\% cure rate on orthotopic MB49 murine bladder tumors treated with an SWCNT-AV conjugate and NIR light. ${ }^{110}$ Furthermore, an increase in photothermal therapy efficiency when using SWCNTs was reported by adding phenoxylated dextran against inflammatory macrophages. ${ }^{111}$

Besides PTT, photodynamic therapy (PDT) can be used to eradicate cancer cells. A photosensitizer absorbs light at a specific wavelength leading to highly toxic reactive oxygen species. ${ }^{112}$ In recent years, there have endeavors to merge PPT, PDT and chemotherapy and the combination is called chemophoto therapy. In this sense, a study decorated PEG on SWCNT. On the other hand, carbon quantum dots (CQDt) with a mean diameter of $2.8 \mathrm{~nm}$ were produced using a hydrothermal technique. Next, with the combination of $\mathrm{Fe}_{3} \mathrm{O}_{4}$ and $\mathrm{CQDt}, \mathrm{Fe}_{3} \mathrm{O}_{4} @ \mathrm{CQDt}$ conjugated on PEGSWCNT formed a simultaneous tool for improved MR/fluorescence imaging. The resultant complex was a porous structure such that DOX could be loaded on the complex. For the specific targeting of cancer cells, an aptamer conjugated multiplex including SWCNT-PEG-Fe $\mathrm{O}_{4} @$ quantum dots/DOXApt was prepared. When the multiplex was used in just PDT therapy, even at the highest doses $(60 \mu \mathrm{g} / \mathrm{mL}), 30 \%$ of the cancer cells remained alive, but at the same dose, more than
$95 \%$ of HeLa cells were destroyed by using a combination of the chemo-photo therapy. ${ }^{113}$

An additional combinatory endeavor merged drug delivery, magnetic resonance imaging (MRI) and optical imaging with PTT. For this, a group of researchers synthesized hyaluronic acid-modified SWCNTs, then conjugated DOX on its surface, and finally added an MRI contrast agent, gadolinium $\left(\mathrm{Gd}^{3+}\right)$, through sidewall defects on the SWCNTs. This provided a multiplex redox-sensitive complex. The release of DOX from the multiplex at $10 \mathrm{mM}$ GSH in vitro was reported to be $19.9 \%$ for the first $4 \mathrm{~h}$ and $35.7 \%$ after $24 \mathrm{~h}$. When the GSH concentration increased up to $20 \mathrm{nM}$, which is the intracellular level reported for tumor cells, the in vitro DOX release increased to $57.7 \%$ and $80.2 \%$ after $4 \mathrm{~h}$ and $24 \mathrm{~h}$, respectively. ${ }^{114}$

Another research study was conducted based on the combinatory nature to evaluate the capability of SWCNTs both as a non-covalent carrier and imaging agent simultaneously. This study applied an aqueous two-phase extraction process to provide two single-chirality SWCNTs. In addition, two therapeutic compounds, PI3 kinase inhibitor (PX-866) and chemokine receptor type 5 (siCRR5), were attached to each specific SWCNT chirality. It means that 7,5 and 7,6 chiral SWCNTs were separated from raw CoMoCAT SWCNT samples ${ }^{108}$ because at those values, the high yield (40\%) emission can be observed at $1035 \mathrm{~nm}$ and $1130 \mathrm{~nm}$, respectively. The internalization of each chiral SWCNTs was confirmed by NIR imaging to confirm the delivery of the drug (PX-866) and gene (siCRR5) to targeted human HepG2 (hepatocarcinoma) cells. The findings for assessing CCR5 siRNAmediated knockdown in HepG2 cells revealed that a much lower expression of CCR5 was observed than the natural expression in the control sample after $48 \mathrm{~h}$ of transfection. ${ }^{115}$

It seems that in recent years, combinatory strategies are gaining more and more attention. Trying to balance surface functionalization, maintaining loading capacity, decreasing the side effects of anticancer drugs with lowering doses, using NIR irradiation to locally heat the cancer spheroids, and designing stimulus-responsive systems are the priorities of such endeavors in oncology studies.

\section{CNTs as Carriers of Immunoactive Compounds, Proteins, and Genetic Materials}

In another attempt to attack melanoma cells, researchers have functionalized specific antigens on the surface of CNTs. For such approaches, CNTs have been designed to 
possess geometries that can penetrate cell membranes. Gangliosides are one of the elements in cell membraneassociated domains, so MWCNTs with a length of 0.5 to 2 $\mu \mathrm{m}$ and a 20-30 $\mathrm{nm}$ diameter have been produced. Next, the MWCNTs were oxidized and shortened to a length of $400 \mathrm{~nm}$ while carboxylic groups formed on the side walls, and then amine groups formed on the MWCNT structure. Finally, the GM-3 lactone mimetic antigen was functionalized on MWCNTs to target melanoma human cells (A357). The results verified that the functionalized CNTs efficiently improved the inhibition of metastatic events (such as adhesion, migration and invasiveness mediated by antigen mimetics) in A357 cells. ${ }^{116}$

Based on triggering antigen delivery to dendritic cells, a MWCNTs-system was designed which modified nanotubes with mannose. At the first step, MWCNTs functionalized with $\mathrm{COOH}$ groups, and then mannose was inserted on their surface and finally, ovalbumin (OVA) was loaded as a model antigen. The confocal images of bone marrow-derived dendritic cells showed that their uptake increased greatly when MWCNT-OVA was used in their vicinity compared to the free OVA, probably because MWCNTs have considerable internalization ability through passive mechanisms. Furthermore, the cellular uptake surged more when using modified MWCNT-OVA with molecular mannose since mannose facilitates the binding between MWCNTs and dendritic cells through ligand/receptor interactions. ${ }^{117}$

While researchers continue to merge various strategies to attack tumor cells, a study established an MWCNT-PEG system and used the CREKA peptide as the targeting moiety on the surface because it has an affinity for fibrin. The central idea of the project was to amplify the antitumor effect by satisfying two requirements. MWCNTPEG was functionalized with the CREKA peptide in the circulatory system to moderate thrombosis in the tumor vessels to possess a large amount of fibrin. Then, fibrin will attract MWCNT-PEG modified with CREKA. ${ }^{118}$

Protein immobilization on CNTs has been used to produce a biosensor for detecting an analyte, but in research conducted by Da Ros et al, MWCNTs were conjugated with the recombinant form of human $\alpha$-L-iduronidase which is an enzyme. Mucopolysaccharidoses is a rare genetic disease in which the absence or deficiency of $\alpha$-L-iduronidase leads to a significant health situation, sometimes including cognitive impairment. This study evaluated human fibroblast samples extracted from the skin of patients having mucopolysaccharidoses type I against MWCNTs conjugated with laronidase (a human recombinant of $\alpha$ L-iduronidase). The results showed that not only could CNTs enter the cells but also they retained enzyme activity after internalization up to $48 \mathrm{~h}$, which is important to mitigate the side effects of mucopolysaccharidoses. ${ }^{119}$

\section{Gene and Small Molecule Delivery (RNA, DNA, and Genes)}

So far, this review has covered the multi-dimensionality properties of CNTs that make them suitable carriers and even an optical agent to help in disease therapy and diagnostics. Here, we will further review what has been achieved in gene delivery with CNTs in the last 5 years. A class of non-coding RNAs that play a role in different biological events are miRNAs. A study demonstrated that functionalizing CNTs with such polymers (like polyethylenimine (PEI) and polyamidoamine (PAMAM)) are proper candidates for miRNA delivery to endothelial cells in order to regulate a target gene (CDC25A), which plays a role in regulating cell proliferation and in vitro angiogenesis. $^{26}$ They have reported that conjugating miR503 with functionalized MWCNTs leads to stabilizing the miRNA against nucleolytic degradation. ${ }^{26}$ Exciting work has focused on producing a device consisting of hollow CNTs for carrying different macromolecules, nanoparticles and DNA sequences ranging from $0.66 \mathrm{kDa}$ to $3900 \mathrm{kDa}$ simultaneously to tens of thousands of cells with high efficiency (the efficiency for plasmid DNA delivery was reported at $84 \%$ ) and with low cytotoxicity. ${ }^{120}$

There have also been some efforts to combine drug and gene delivery purposes through CNT vectors. For example, research conducted by $\mathrm{Cao}$ et al functionalized SWCNTs with polyetherimide (PEI) conjugated with betaine (PB). If we are allowed to call this multiplex as mentioned in the original article as SWCNT-PB "(SPB)", it can be said that this provides a great $\mathrm{pH}$-responsive lysosomal escape ability for siRNA. The SPB surface was further modified with a BR2 peptide to enhance its tendency for siRNA. Finally, the DOX-SPBB-siRNA produced was tested against an A549 cancer cell line. In vitro results demonstrated that the apoptotic rate for free siRNA, SPB and SBP-penetrating peptide BR2 (SPBB) was $2.0 \%, 11.7 \%$ and $24.4 \%$, respectively. The tumor inhibition in vivo (tested in a murine model bearing A549 tumor cells) for DOX-SPBB ( $5 \mathrm{mg} \mathrm{kg}^{-1}$ of DOX) vs DOX-SPBB-siRNA (containing $2 \mathrm{mg} \mathrm{kg}^{-1}$ of siRNA) was reported to be $48.31 \%$ and $69.22 \%$, respectively. The 
main goal of adding siRNA to the anticancer drug (DOX) for delivery with SWCNTs was to silence the expression of surviving proteins to prevent the normal apoptotic cycle in cells ${ }^{121}$ (Figure 2).

Another example of these synergistic effects was tried in a study that synthesized functionalized SWCNTs with PEG and PEI conjugated with an aptamer to co-deliver a low dose DOX and Bcl-xL shRNA to gastric cancer cell lines. Results showed that the presence of an AS1114 aptamer in a multiplex consisting of Apt-SWCNT-PEG $-10-10 \%-\mathrm{PEI} / \mathrm{pBcl}-\mathrm{xL}$ shRNA can reduce the expression of Bcl-xL up to $104.4 \%$ while the multiplex without aptamer (SWCNT-PEG-10-10\%-PEI/pBcl-xL shRNA) showed a lower decrease of $76.1 \%$ in Bcl-xL expression in $\mathrm{L} 929$ cells after $72 \mathrm{~h}$. An advantage of their work was that they could lower the dose of DOX to $100 \mathrm{nM}$, which is 58 -fold lower than the IC50 doses calculated for free DOX to reduce the anti-cancer drug's side effects significantly. The results demonstrated that decreases in cell viability for AGS cells against free DOX and SWCNT-PEG-PEI /pBcl-xL shRNA-Apt were $77 \%$ and $45 \%$, respectively. ${ }^{67}$

However, using CNTs as deliverer of siRNA is not restricted only to animal cell studies. For example, research conducted by Landry et al practiced SWCNT as an effective platform for post-transcriptional gene silencing in intact cells of mGFP5 Nicotiana benthamiana plants. In this study, siRNA loaded on pristine SWCNTs by probe-sonication technique and two sets of single stranded siRNA included both sense and antisense strands. Those SWCNTs, purchased from NanoIntegris, showed the average length size of $776 \mathrm{~nm}$ while the other group of SWCNTs got shorter to the mean length of $250 \mathrm{~nm}$ through further probe-tip sonication process. The internalization efficacy was investigated for both groups of NPs in GFP benthamiana cells. So, the shorter nanotubes had a lower efficacy of $47 \%$ compared to the acceptable rate of $70 \%$ for the longer SWCNTs. The silencing studies confirmed that the optimal amount for silencing mGFP5 is $100 \mathrm{nM}$ of siRNA on $2 \mathrm{mg} / \mathrm{L}$ SWCNTs. ${ }^{122}$

Moreover, in plant studies, a plant genetic engineering technique suggested applying SWCNTs to selectively carry plasmid DNA into chloroplast of various plant species without any need for chemical or biolistic aid. So, chitosan-complexed SWCNTs was loaded with pDNA prepared for this study and the pDNA unloading mechanism was studied in the basic environment of $\mathrm{pH} 8$, which is

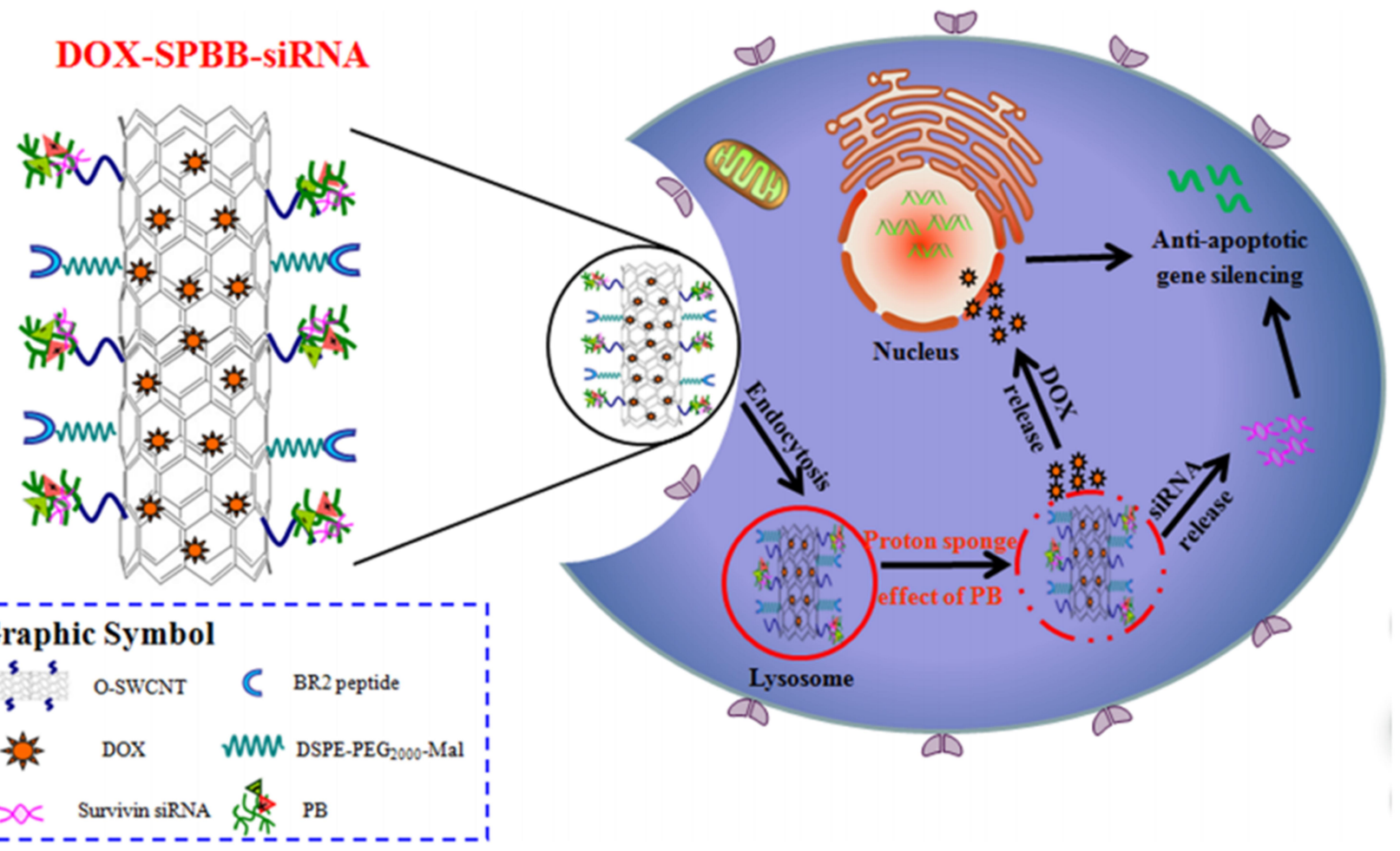

Figure 2 Schematic illustration of DOX-SPBB-siRNA nanocarriers for treating lung cancer cells.

Notes: Reprinted with permission from Cao Y, Huang HY, Chen LQ, et al. Enhanced Lysosomal Escape of pH-Responsive Polyethylenimine-Betaine Functionalized Carbon Nanotube for the Codelivery of Survivin Small Interfering RNA and Doxorubicin. ACS Appl Mater Interfaces. 20I9; I ( I0):9763-9776. Copyright (C (20I9) American Chemical Society. ${ }^{121}$ 
similar to the chloroplast stroma. It seems that SWCNTpDNA follows the lipid exchange envelope penetration (LEEP) model in which the prevalent factors for the delivery of NPs for penetration into cell membranes and chloroplast are size and surface charge. Therefore, by tuning different physical and optical properties, the research could target various plant species including mature arugula, mature wild-type watercress ( $N$. officinale), spinach (S. oleracea) and tobacco (N. tabacum) plants. ${ }^{123}$

Moreover, it has been suggested to combine gene delivery and a stimulus-responsive strategy to make a photoactivable RNAi for cancer gene therapy. In this research, SWCNTs functionalized with PEI acted as a stimulus-responsive nanocarrier. On the other hand, anpHSP-shT was used as an Hsp70B-promoter-driver RNAi vector. By irradiating with NIR light, PEISWCNTs started to heat, and then activated the gene knockdown targeting human telomerase reverse transcriptase by RNAi. ${ }^{124}$

Pantarotto et al synthesized a first generation of ammonium f-CNTs using it for mammalian cell pDNA delivery. Here, ionic interactions were established between the positive charges of ammonium f-CNTs and phosphate groups of pDNA, and the expression level of the $\beta$-galactosidase marker in the $\mathrm{CHO}$ cells was about 10 times greater than when the naked pDNA was observed. ${ }^{125}$ In fact, it is believed that the cationic groups in CNTs bound to the membrane of the cells and facilitated their passage through the cell membrane.

Furthermore, $\mathrm{Hu}$ et al used SWCNTs for vaccine (recombinant plasmid pcDNA-ORF149) delivery against Koi herpesvirus (KHV) in fish. According to the analyses on the expression levels of mRNAs related to cytokine (cxca, il1 $\beta$ ) interferon-stimulated genes (mx1, vip2), this study concluded that higher expression levels were achieved when SWCNT-p149 was applied in carps compared to free p149 vaccine. ${ }^{126}$

Also, Hashem Nia et al produced PEI-disulfide-SWNT conjugates and showed a 1500 time increase in transfection efficiency reducing toxicity compared to PEI $25 \mathrm{kDa}$. In fact, they designed a library of 15 different carrier types, consisting of the conjugation of SWNT and PEIs through different spacers and oxidative disulfide bonding, and concluded that the presence of bioreducible disulfide bond leads to the production of vectors that after placing it inside a cell, converts it to small molecules to reduce toxicity. Most studies conducted on the use of CNTs use an easy-to-transfect-cell line and there are very few studies on the in vivo environment. ${ }^{127}$ In addition to studies on easy-to-transfect cell lines, some studies have been carried out on mammalian primary cells including fibroblastic cells, which are also part of the hard-to-transfect cells, and embryonic cells and through further study obtained useful results on the effect of gene delivery to these cells; more hope for the combination of gene carriers with CNTs in vivo results from such work.

Munk et al ${ }^{128}$ synthesized COOH-MWCNTs and added them to bovine primary fibroblast cells in order to release the pDNA encoding a green fluorescent protein gene. They concluded that these COOH-MWCNTs-pDNA led to successful transfection into the primary cells and as such, a less toxic transfection method was developed. Furthermore, a study showed that MWCNTs with diameters of 20-40 $\mathrm{nm}$ and lengths of $40-60 \mu \mathrm{m}$ can be proper carriers for the delivery of pDNA into in vitro fertilized bovine embryos. The results demonstrated that MWCNTs did not affect the degeneration rate and gene expression related to cell viability. $^{129}$ Also, efficient pDNA transfer to primary cells is still limited and there is a high need for further studies on the maintenance of DNA from degrading enzymes and reducing toxicity and damage to normal cells in vivo. Table 5 reviews other articles similar to those mentioned earlier concerning CNTs specifically used for various molecular delivery applications.

\section{Other Applications (Tissue Engineering, Sensors, and Infectious Diseases)}

What has been discussed so far are certainly not the only applications of CNTs in medicine. CNTs have also been used in microfluidics, ${ }^{130}$ tissue engineering, sensors, and infectious diseases as described below.

In the tissue engineering discipline, it has been suggested that a composite made of hydroxyapatite and MWCNTs filled with iron can improve bone tissue formation to develop an implant that can withstand orthopedic mechanical loading. A study reported that the compressive strength and Young's modulus of HA-Alg/MWCN+Fe were 168 and $740 \mathrm{MPa}$, respectively, ${ }^{131}$ while those values are reported to be 141 and $338 \mathrm{MPa}$ for male human cortical femur bone and 118 and $404 \mathrm{MPa}$ for female human cortical femur bone. ${ }^{132}$ It seems that a composite made of $\mathrm{Alg} / \mathrm{MWCNT}+\mathrm{Fe}$ can fill bone defects with distinctive geometries considering the advantages of the prolonged release of chlorhexidine as a model from the composite. $^{131}$ 
Table 5 Other Examples of CNTs Used for the Delivery of Molecules

\begin{tabular}{|c|c|c|c|c|c|c|}
\hline CNTs & Molecules & Functional Group & Particle Size & $\begin{array}{l}\text { Release } \\
\text { Control }\end{array}$ & $\begin{array}{l}\text { In } \\
\text { vitro/ } \\
\text { in vivo }\end{array}$ & Ref. \\
\hline SWCNTs & $\begin{array}{l}\text { Carnosine } \\
\text { dipeptide }\end{array}$ & $\begin{array}{l}\text { Modified with PEG at the lysine residues via } \\
\text { amide bonds }\end{array}$ & - & - & - & [172] \\
\hline SWNTs & DOX & Modified with oxidative acid and PEG-g-PEI & Diameter $\mathrm{I}-2 \mathrm{~nm}$, length $\mathrm{I}-3 \mathrm{~nm}, \mathrm{SSA} 380 \mathrm{~m}^{2} / \mathrm{g}$ & Acidic pH & In vitro & [173] \\
\hline MWCNTs & DOX & $\begin{array}{l}\text { Functionalized with (TAT)-chitosan } \\
\text { (MWCNTs-TC) }\end{array}$ & - & - & $\begin{array}{l}\text { In vivo, } \\
\text { in vitro }\end{array}$ & [174] \\
\hline SWCNT & DTX & $\begin{array}{l}\text { Functionalized with iron oxide NPs and } \\
\text { coated by PLA co-mPEG micelles }\end{array}$ & $\sim 15-50 \mathrm{~nm}$ & $\begin{array}{l}\text { External } \\
\text { magnetic } \\
\text { fields }\end{array}$ & $\begin{array}{l}\text { In vivo, } \\
\text { in vitro }\end{array}$ & [175] \\
\hline SWCNT & $\begin{array}{l}\text { EGFP } \\
(n E G F P)\end{array}$ & Functionalized with streptavidin & $\sim 200 \mathrm{~nm}$ in length & $\begin{array}{l}\text { Light- } \\
\text { responsive }\end{array}$ & $\begin{array}{l}\text { In vivo, } \\
\text { in vitro }\end{array}$ & [176] \\
\hline MWCNT & $\begin{array}{l}\text { Zolpidem } \\
\text { (ZM) }\end{array}$ & Modified with D-glucose (GI) & $\begin{array}{l}\text { Diameter of MWCNTCOOH } 10 \mathrm{~nm}, 27 \mathrm{~nm} \text { in } \\
\text { MWCNT-GI }\end{array}$ & - & In vitro & [177] \\
\hline SWNTs & DOX & Non-covalently functionalized with PL-PEG & $\begin{array}{l}\sim 1 \mathrm{~nm} \text { and } \sim 1.2 \mathrm{~nm} \text { inner and outer diameters, } \\
50-200 \mathrm{~nm} \text { PEG-coated SWNTs }\end{array}$ & $\begin{array}{l}\text { NIR } \\
\text { irradiation }\end{array}$ & In vitro & [178] \\
\hline MWCNT & DTX & $\begin{array}{l}\text { Chitosan-folate (CHI-FA) conjugated } \\
\text { MWCNT }\end{array}$ & $\sim 230$ to $483 \mathrm{~nm}$ in length & - & $\begin{array}{l}\text { In vivo, } \\
\text { in vitro }\end{array}$ & [179] \\
\hline MWCNTs & $\begin{array}{l}\text { Antigenic } \\
\text { protein } \\
\text { (OVA) }\end{array}$ & Modified with lentinan & $9-10 \mathrm{~nm}$ in diameter, $1-2 \mu \mathrm{m}$ in length & - & $\begin{array}{l}\text { In vivo, } \\
\text { in vitro }\end{array}$ & [180] \\
\hline
\end{tabular}

There are also endeavors to apply CNTs to stem cell studies. It has been shown that CNTs can improve the differentiation in stem cells and be formulated to create features like natural neurological tissues. A study used hydrophobic and hydrophilic CNTs impregnated with subventricular zone neural progenitor cells (SVZ NPCs) to help the healing process in a murine model after stroke. The findings showed that hydrophobic CNTs could improve the rat behavior and decrease the cyst volume in comparison with the controls (no treatment) and a hydrophilic CNTs-SVZ NPC group. ${ }^{133}$

In addition, the effectiveness of polypyrrole (PPy) films on a platform made of MWCNTs grown out of anodized nanotubular titanium (MWCNT-Ti) was highlighted in a smart drug delivery system. PPy is a conductive polymer which can hold drugs such as antibiotics (penicillin/streptomycin) or anti-inflammatory drug (dexamethasone) and release them by electrical stimulation, on-demand and remotely. The findings through cyclic voltammetry confirmed that up to $80 \%$ of the drugs were released whenever five cycles of sweep voltages were applied at a scan rate of $0.1 \mathrm{~V} \mathrm{~s}^{-1}$. Additionally, the PPydrug films increased osteoblast (bone-formation) adhesion in vitro. ${ }^{134}$ Thus, just from these examples, one can see an incredible future for the use of CNTs across all medicine.

\section{Other Nanotubes}

When carbon nanotubes were introduced, a new paradigm emerged in synthesizing nanotubes as hollow closed structures from reactive metal and non-metal rim atoms. This new approach suggested methods to folding nanolayers of 2D material into 3D tubular hollow structures, such as it produces more energy to compensate for the elastic energy of folding. The primary rationale behind nanotubular synthesis relies on the intrinsic instability of nascent 2D crystalline layered structures in the planar form. ${ }^{135}$ Other nanotube structures that have been introduced are metal-organic framework (MOF) nanotubes, mono and mixed metal oxide nanotubes, and halloysite nanotubes. MOFs consist of organic-inorganic hybrid coordination networks in which the surface area, pore volume, pore size and their functionality can be tuned accurately. MOFs are composed of metal ions bridged by organic (polymeric) ligands. ${ }^{136}$ For instance, Wei et al provided a single-crystal metal-organic framework as an elongated tubular capsule that can deliver large amounts of sulfur and iodine within its structures. In this 
research, an iron-nickel-based single crystal MOF provided from transformations at the molecular level of a crystal structure. They have used non-hollow nanocrystals of FeNiMIL-88B as the self-templated agent in hot $\mathrm{N}$, N-dimethylformamide. ${ }^{137}$ Other reports such as ${ }^{138}$ show that nanotubular topography improves the bioactivity on titanium implants. In addition, this report demonstrates that $\mathrm{TiO}_{2}$ nanotubes facilitate the process of osteogenesis in a rabbit model, so $\mathrm{TiO}_{2}$ nanotubes are favorable coatings in terms of enhancing the performance of endosseous implants. ${ }^{138}$ Another class of nanotubes which have been widely studied are halloysite nanotubes which have aluminosilicate structures that can be functionalized with various compounds such as organosilanes, polymers, biomacromolecules, surfactants and other nanomaterials both on their inner lumen and outer surface for different applications. ${ }^{139}$ For instance, chitosan modified halloysite nanotubes have been applied as a carrier of norfloxacin, an antibacterial drug. This nanocomposite showed acceptable antimicrobial effects and biocompatibility in cytotoxicity studies. These hollow structures also could sustain drug release from the carrier during in vitro investigations. ${ }^{140}$

\section{Toxicology and Environmental Concerns}

Although the ability of CNTs is undeniable in medical research, especially as useful drug and gene nanocarriers, the failure to reach a definitive conclusion about their toxicity has prevented a futuristic positive opinion for the use of CNTs to enter clinical trials. The biocompatibility of CNTs and their possible harmful effects on cells has attracted much attention from researchers because, in recent years, with the ever-increasing use of CNTs in medicine and their greater presence in the environment, there is a significant proposed relationship between CNTs and some diseases, including respiratory and skin diseases. ${ }^{141-143}$ Importantly, CNTs have the ability to accumulate in tissues (like the heart, spleen, brain, and others) as well as producing oxidative stress and damage to healthy cells. ${ }^{144,145}$ But today, it is known that CNT properties (such as physical dimensions, area, dose, ratio of length to diameter, time, purity and the presence of chemical agents bound to the surface), each one, in turn, can improve CNT cytotoxicity; one simply needs to pay attention to those properties. All CNTs are not the same and, thus, they should not all be painted with the same toxicity profile, a lesson some have still not learned.

\section{Effect of Length and Diameter on CNT Toxicity}

The length and diameter of CNTs impact how well they penetrate the membranes of macrophages or are internalized in cells. For example, shorter MWCNTs (ranging from 100 to $600 \mathrm{~nm}$ in length) indicated a lower level of cytotoxicity to human umbilical vein endothelial cells (HUVECs) compared with longer (ranging from 200 to $2000 \mathrm{~nm}$ ) MWCNTs. ${ }^{146}$ It was found that most longer MWCNTs promoted a higher depletion of intracellular GSH and oxidative stress. ${ }^{146}$

Different diameters (thicker versus thinner) and rigidity (determined by the length and diameter of CNTs) can be influential to cellular toxicity. For example, Cifuentes-Rius et al compared the accumulation of flexible (fCNTs, $1-5 \mu \mathrm{m}$ long and $15 \mathrm{~nm}$ in diameter) and rigid and shorter CNTs (rCNTs and s-rCNTs, 5-9 $\mu \mathrm{m}$ long and $110-170 \mathrm{~nm}$ in diameter) using ex vivo fluorescence imaging in each organ of a mouse with in vivo imaging. They concluded that fCNTs were more likely to accumulate in organs and form a toxic tangle in solution ${ }^{29}$ (Figure 3). Regarding the length of MWCNTs, several studies have shown that CNTs with longer lengths and larger diameters have greater toxicity than smaller ones. ${ }^{34}$ Another group has also shown that short CNTs do not result in damage to cells. Despite the fact that most studies have shown that longer and wider CNTs lead to greater toxicity, some researchers have found the opposite. ${ }^{36,37}$

\section{The Effect of CNT Aggregation}

CNTs are foreign agents after entering the living body and the immune system can be activated attempting to phagocytose them via immune cells, including macrophages. The results can be an extensive inflammatory reaction and fibrosis. As already mentioned, CNT aggregation in tissues (like the heart, lung, brain, and others) can produce oxidative stress and damage to healthy cells. Principi et al used in vivo systematic models in different organs (eg, the liver, kidney, spleen and lung) to monitor CNT aggregation. They explained the transient aggregation of SWCNTs $(2-5 \mu \mathrm{m}$ in length and $1.2 \mathrm{~nm}$ in diameter) in the kidney, spleen and lungs of CD1 mice, but the liver was the favored organ for the aggregation of CNTs, which can cause inflammation and oxidative stress. In general, the results from the aggregation of CNTs in the liver over the long-term show that caution should be used for CNT applications. ${ }^{147}$ 


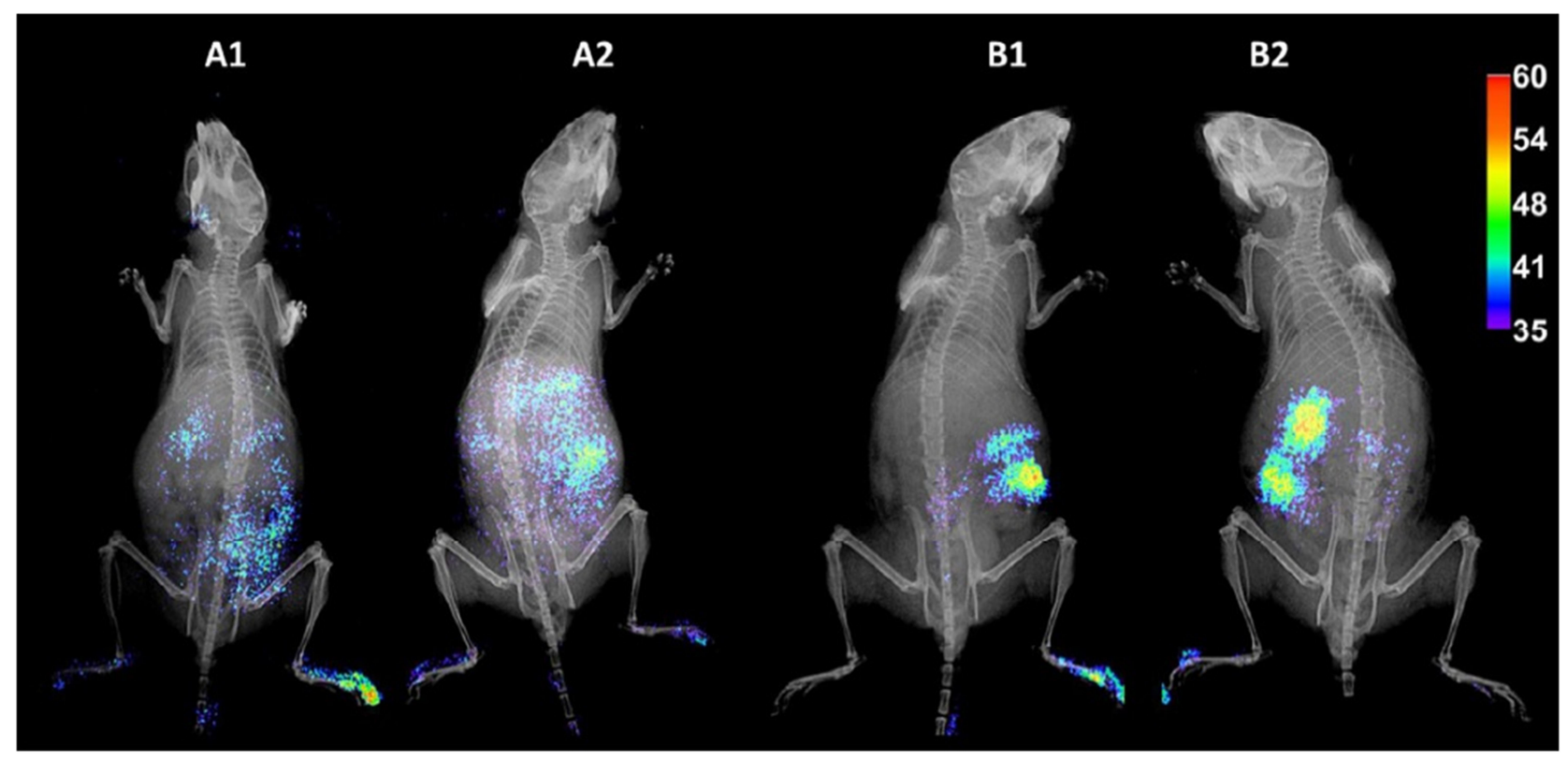

Figure 3 In vivo biodistribution of fluorescent-labeled rCNT (AI and A2) and fCNT (BI and B2) in mice.

Notes: Reprinted with permission from Cifuentes-Rius A, Boase NRB, Font I, et al In Vivo Fate of Carbon Nanotubes with Different Physicochemical Properties for Gene Delivery Applications. ACS Appl Mater Interfaces. 2017;9(13):II,46I-II,47I. Copyright (2017) American Chemical Society. ${ }^{29}$

\section{Effect of CNT Functionalization}

The functionalization of CNTs has a beneficial effect on better dispersion in solution and decreases in toxicity as well as increases in bioaccumulation and purification. For example, macrophages exposed to poly(dopamine) (PDA)functionalized MWCNTs improved aqueous dispersibility and their versatility and decreased the production of inflammatory factors and cytokines. ${ }^{148}$ CNTs functionalized by DOX (CNT-DOX) established lower organism toxic effects compared to free DOX, and also decreased the toxicity of DOX on the general indicators of blood in vivo. ${ }^{149}$ Table 6 lists some of the best ways to reduce the toxicity profile of CNTs both in vitro and in vivo.

However, it is critical to note that it has been very difficult for the scientific community to reach a consensus in CNT toxicity because of faults of the studies themselves. For example, the literature often presents in vivo toxicity profiles of CNTs introduced into animals that do not resemble how they would enter the body in real life. More disturbingly, many studies do not even accurately characterize the purity and other material properties emphasized in this review which clearly have an influence on CNT toxicity. Until we have studies that accurately characterize the materials being tested and mimic the ways in which CNTs would enter the body in "real life", the promising properties of CNTs will never reach the clinic.

\section{Conclusions and Future Directions}

Drug/gene delivery is one of the most widely used applications of CNTs in biomedicine. In recent years, various solutions have been proposed for loading small molecules, such as anticancer drugs, on nanotubes in the form of covalent bonds or non-covalent absorption. Aromatic molecules can also be adsorbed onto the surface of nanotubes by $\pi-\pi$ bonds; for example, the binding of DOX through $\pi-\pi$ bonds to PEGylated CNTs. ${ }^{102}$ Cellular uptake and its internalization mechanisms are affected by different physicochemical properties of CNTs and the type of cell itself. CNTs are able to act as carriers of anticancer molecules, including docetaxel (DTX), doxorubicin (DOX), methotrexate (MTX), paclitaxel (PTX), and gemcitabine (GEM), etc. The unique properties of CNTs also enable them to efficiently deliver pDNA, siRNA, and miRNA.

Compared to drug/gene delivery system-based biodegradable organic materials, CNTs may not have noticeable benefits if they are simply applied as drug/gene carriers, since they hardly degrade when made conventionally. However, if not created correctly, CNTs have the ability to accumulate in tissues like the heart, spleen, brain, and others, as well as produce oxidative stress and damage to healthy cells. Hence, the possible toxicity of CNTs is a major concern raised with regard to biomedical applications of CNTs. On the other hand, surface 
Table 6 Cell Viability and in vivo Toxicity Results for Various Concentrations of Functionalized-CNTs

\begin{tabular}{|c|c|c|c|c|}
\hline Types of Functionalized CNTs & $\begin{array}{l}\text { In vito/in vivo } \\
\text { Model }\end{array}$ & Cell Viability/in vivo Results & $\begin{array}{l}\text { Concentration of CNTs } \\
\qquad(\mu \mathrm{g} / \mathrm{mL})\end{array}$ & Ref. \\
\hline FA- MWCNTs & HeLa cells & $>90 \%$ & - & [99] \\
\hline MWCNT-COOH & HEK 293 cells & $91.96 / 47.78 \%$ & $25 \mu \mathrm{g} / \mathrm{mL} / 300 \mu \mathrm{g} / \mathrm{mL}$ & [18I] \\
\hline MWCNT-COOH & Zebra fish embryos & Non-significant decrease in survival rate & - & {$[181]$} \\
\hline $\begin{array}{l}\text { PLL-CNT@PDA film, PLL-CNT-COOH } \\
\text { film }\end{array}$ & RAW264.7 cells & No viability changes in cells & - & [148] \\
\hline SWCNT-PB (SPB) & 293T and A549 cells & $>80 \%$ & $50 \mu g / m L$ & {$[121]$} \\
\hline $\begin{array}{l}\text { Tangled oxidized multi-walled CNTs } \\
\text { (t-ox-MWCNTs) }\end{array}$ & Wistar strain rat & $\begin{array}{l}\text { Low toxicity and long-term biopersistence of the t-ox- } \\
\qquad \text { MWCNTs in vivo }\end{array}$ & $<100 \mu \mathrm{g}$ & [182] \\
\hline PEGylated SWNT & $\begin{array}{l}8-12 \text { to week-old } \\
\text { nude mice }\end{array}$ & Toxicity of high doses was not observed in nude mice & $151 \mathrm{mg}$ of PEG-SWNT & [183] \\
\hline
\end{tabular}

functionalization and modification of CNT physical properties are effective ways to reduce their cytotoxicity. Various in vivo toxicological studies have shown that the functionalized CNTs can be established as improved low toxic nanomaterials over non-functionalized CNTs. Functionalization of CNTs with lipid head groups is just one way to solve their toxicity concerns. It also makes them easier and faster to move inside the body, reducing the risk of clogging vital arteries, making it a great choice for use as a carrier. ${ }^{150}$ In general, the use of CNTs has not yet been tested in the human body, and their use for clinical applications is still early, but there is no doubt that these carriers are promising for numerous medical applications and require further research.

In general, it is necessary to have an accurate understanding of the pharmacological and toxicological properties of CNTs before using them in clinical applications. The optimal performance of CNTs for specific biomedical applications should be considered, whereas surface chemistry is designed to minimize toxicity. Parameters such as distribution, aggregation rate, and clearance pathways for CNT-based drug/gene delivery systems should also be considered.

\section{Expert Opinion}

In recent decades, nanomaterials have attracted significant attention from researchers, arguably the most attention of any material category. Hence, nanomedicine has significantly expanded during recent years. Among other nanomaterials, CNTs as an allotrope of carbon have been able to attract great interest in this field of research because of attractive physicochemical and structural properties. The intrinsic properties of CNTs have led to a large quantity of research studies. These studies have attempted to use CNTs as promising candidates for numerous biomedical applications, and make them suitable for medicine, including serving as drug delivery systems, gene delivery and gene therapy vectors, bioimaging, diagnostic applications, biosensors, and vaccine delivery. The electrical, optical, mechanical and thermal properties of CNTs make them a very attractive material for the detection and therapy of cancers and other diseases.

One of the most important biomedical applications of CNTs is their use as drug delivery and gene delivery which is the topic of this review. This review, in which a wide range of research studies especially from the years 2016-2020 were discussed and is an update on our previous work regarding drug delivery and gene delivery applications of CNTs. The internalization of CNTs by cells is not a monotonic process and can be both a plus and negative for CNTs. They can be internalized through passive or active uptake mechanisms to delivery drugs and genes. The needle-like shape of CNTs allows them to directly transfer to cell membranes through a passive mechanism. Also, CNTs can be taken up by cells via endocytosis pathways which is an energy-dependent mechanism unlike the passive pathway. The structural and surface features of CNTs are the most influential factors in the behavior of CNTs towards cells; hence, the biological effects of these factors need to be investigated. Optimization and modification of these characteristics can lead to success in delivering different drugs and genes. However, the ability of CNTs to enter cells can also be a disadvantage in terms of unwanted toxicity. 
Nanotoxicology aspects of CNTs (including environmental effects) need to be fully studied. Regardless of the knowledge acquired in recent years on nanotoxicology, scientists have not yet been able to precisely forecast the behavior and biokinetics of CNTs.

As a future perspective, the advantages and disadvantages of CNTs should be weighed against that of other drug delivery systems since each of these systems has pros and cons considering the type of disease, delivery path, drug molecule properties, and DNA sequence. Regardless of recent advances in the field of nanotoxicology, there is still a need to assuage concerns regarding the probable toxic effects of CNT applications in medicine, and for that, we all need to design better experiments to provide definite answers.

\section{Abbreviations}

Apt, aptamer; CQDt, carbon quantum dots; CNTs, carbon nanotubes; CS, chitosan; $\mathrm{CD}$, cyclodextrin; DEX, dexamethasone; DSPE, distearyl phosphatidyl ethanolamine; DTX, docetaxel; DOX, doxorubicin; DDSs, drug delivery systems; GEM, gemcitabine; GSH, glutathione; HP- $\beta-\mathrm{CD}$, hydroxypropyl- $\beta$-cyclodextrin; HA, hyaluronic acid; HUVECs, human umbilical vein endothelial cells; FA, folate acid; FMN, formononetin; MRI, magnetic resonance imaging, MWCNTs, multi-walled CNTs; MTX, methotrexate; PTX, paclitaxel; PTT, photothermal therapy; PDT, photo dynamic therapy; PI, pDNA, phospholipid; plasmid DNA; PAMAM, polyamidoamine; PDA, poly(dopamine); PEG, polyethylene glycol; PEI, polyethylenimine; PPy, polypyrrole; rCNTs, shorter CNTs; SWCNTs, single-walled CNTs; siRNA, small interfering RNA; shRNA, small hairpin RNA; SVZ, subventricular zone; THFF, tetrahydrofurfuryl; ZM, zolpidem.

\section{Acknowledgments}

The authors want to acknowledge Sharif University of Technology, Tehran, Iran as well as Northeastern University, Boston, MA, USA for their support.

\section{Disclosure}

Michael R Hamblin reports personal fees from Vielight, outside the submitted work. The authors report no conflicts of interest in this work.

\section{References}

1. Rahim M, Rizvi SMD, Iram S, Khan S, Bagga PS, Khan MS. Chapter 5 Interaction of green nanoparticles with cells and organs. In: Grumezescu AM, editor. Inorganic Frameworks as Smart Nanomedicines. William Andrew Publishing; 2018:185-237.
2. Gao H, Jiang X. Chapter 1 - the medical applications of nanomaterials in the central nervous system. In: Jiang X, Gao H, editors. Neurotoxicity of Nanomaterials and Nanomedicine. Academic Press; 2017:1-31.

3. Wei M, Li S, Le W. Nanomaterials modulate stem cell differentiation: biological interaction and underlying mechanisms. J Nanobiotechnology. 2017;15:75. doi:10.1186/s12951-017-0310-5

4. Higuchi M, Takagi H, Owada Y, et al. Efficacy and tolerability of nanoparticle albumin-bound paclitaxel in combination with carboplatin as a late-phase chemotherapy for recurrent and advanced non-small-cell lung cancer: a multi-center study of the Fukushima lung cancer association group of surgeons. Oncol Lett. 2017;13:4315+. doi:10.3892/ol.2017.5998

5. Karimi M, Zare H, Bakhshian Nik A, et al. Nanotechnology in diagnosis and treatment of coronary artery disease. Nanomedicine. 2016;11:513-530. doi:10.2217/nnm.16.3

6. Shi J, Kantoff PW, Wooster R, Farokhzad OC. Cancer nanomedicine: progress, challenges and opportunities. Nat Rev Cancer. 2017;17:20-37.

7. Ruenraroengsak P, Chen S, Hu S, et al. Translocation of functionalized multi-walled carbon nanotubes across human pulmonary alveolar epithelium: dominant role of epithelial type 1 cells. ACS Nano. 2016;10:5070-5085. doi:10.1021/acsnano.5b08218

8. You DG, Deepagan VG, Um W, et al. ROS-generating TiO2 nanoparticles for non-invasive sonodynamic therapy of cancer. Sci Rep. 2016;6:23200. doi:10.1038/srep23200

9. Simeonidis K, Martinez-Boubeta C, Rivera-Gil $P$, et al. Regeneration of arsenic spent adsorbents by $\mathrm{Fe} / \mathrm{MgO}$ nanoparticles. J Chem Technol Biotechnol. 2017;92:1876-1883. doi:10.1002/jctb.5187

10. Zhang J, Tang H, Liu Z, Chen B. Effects of major parameters of nanoparticles on their physical and chemical properties and recent application of nanodrug delivery system in targeted chemotherapy. Int J Nanomed. 2017;12:8483-8493. doi:10.2147/ IJN.S148359

11. Kumar S, Rani R, Dilbaghi N, Tankeshwar K, Kim K-H. Carbon nanotubes: a novel material for multifaceted applications in human healthcare. Chem Soc Rev. 2017;46:158-196.

12. Cai Z, Zhang H, Wei Y, Cong F. Hyaluronan-inorganic nanohybrid materials for biomedical applications. Biomacromolecules. 2017;18:1677-1696. doi:10.1021/acs.biomac.7b00424

13. Cabrera I, Abasolo I, Corchero JL, et al. $\alpha$-galactosidase-a loadednanoliposomes with enhanced enzymatic activity and intracellular penetration. Adv Healthc Mater. 2016;5:829-840. doi:10.1002/ adhm.201500746

14. Karimi M, Ghasemi A, Zangabad PS, et al. Smart micro/nanoparticles in stimulus-responsive drug/gene delivery systems. Chem Soc Rev. 2016;45:1457-1501.

15. Costa PM, Bourgognon M, Wang JTW, Al-Jamal KT. Functionalised carbon nanotubes: from intracellular uptake and cell-related toxicity to systemic brain delivery. J Control Release. 2016;241:200-219. doi:10.1016/j.jconrel.2016.09.033

16. Alshehri R, Ilyas AM, Hasan A, Arnaout A, Ahmed F, Memic A. Carbon nanotubes in biomedical applications: factors, mechanisms, and remedies of toxicity. J Med Chem. 2016;59:8149-8167. doi:10.1021/acs.jmedchem.5b01770

17. Foo ME, Gopinath SCB. Feasibility of graphene in biomedical applications. Biomed Pharmacother. 2017;94:354-361. doi:10.1016/j.biopha.2017.07.122

18. Sajid MI, Jamshaid U, Jamshaid T, Zafar N, Fessi H, Elaissari A. Carbon nanotubes from synthesis to in vivo biomedical applications. Int J Pharm. 2016;501:278-299.

19. Skwarecki AS, Milewski S, Schielmann M, Milewska MJ. Antimicrobial molecular nanocarrier-drug conjugates. Nanomedicine. 2016;12:2215-2240. doi:10.1016/j.nano.2016.06.002 
20. Singh B, Lohan S, Sandhu PS, Jain A, Mehta SK. Chapter 15 functionalized carbon nanotubes and their promising applications in therapeutics and diagnostics. In: Grumezescu AM, editor. Nanobiomaterials in Medical Imaging. William Andrew Publishing; 2016:455-478.

21. Azqhandi MHA, Farahani BV, Dehghani N. Encapsulation of methotrexate and cyclophosphamide in interpolymer complexes formed between poly acrylic acid and poly ethylene glycol on multi-walled carbon nanotubes as drug delivery systems. Mater Sci Eng C. 2017;79:841-847. doi:10.1016/j.msec.2017.05.089

22. Ilbasmis-Tamer S, Unsal H, Tugcu-Demiroz F, Kalaycioglu GD, Degim IT, Aydogan N. Stimuli-responsive lipid nanotubes in gel formulations for the delivery of doxorubicin. Colloids Surf B. 2016;143:406-414. doi:10.1016/j.colsurfb.2016.03.070

23. Sharma P, Jain K, Jain NK, Mehra NK. Ex vivo and in vivo performance of anti-cancer drug loaded carbon nanotubes. J Drug Deliv Sci Tech. 2017;41:134-143. doi:10.1016/j.jddst.2017.07.011

24. Srivastava I, Misra SK, Ostadhossein F, Daza E, Singh J, Pan D. Surface chemistry of carbon nanoparticles functionally select their uptake in various stages of cancer cells. Nano Res. 2017;10:3269-3284. doi:10.1007/s12274-017-1518-2

25. Fedeli S, Brandi A, Venturini L, et al. The "click-on-tube" approach for the production of efficient drug carriers based on oxidized multi-walled carbon nanotubes. $J$ Mater Chem $B$. 2016;4:3823-3831. doi:10.1039/C6TB00304D

26. Masotti A, Miller MR, Celluzzi A, et al. Regulation of angiogenesis through the efficient delivery of microRNAs into endothelial cells using polyamine-coated carbon nanotubes. Nanomedicine. 2016;12:1511-1522. doi:10.1016/j.nano.2016.02.017

27. Sun H, Ren J, Qu X. Carbon nanomaterials and DNA: from molecular recognition to applications. Acc Chem Res. 2016;49:461-470. doi:10.1021/acs.accounts.5b00515

28. Kong F, Liu F, Li W, et al. Smart carbon nanotubes with laser-controlled behavior in gene delivery and therapy through a non-digestive trafficking pathway. Small. 2016;12:6753-6766. doi:10.1002/smll.201601092

29. Cifuentes-Rius A, Boase NRB, Font I, et al. In vivo fate of carbon nanotubes with different physicochemical properties for gene delivery applications. ACS Appl Mater Interfaces. 2017;9:11461-11471. doi:10.1021/acsami.7b00677

30. Spinato C, Giust D, Vacchi IA, Ménard-Moyon C, Kostarelos K, Bianco A. Different chemical strategies to aminate oxidised multi-walled carbon nanotubes for siRNA complexation and delivery. J Mater Chem B. 2016;4:431-441. doi:10.1039/C5TB02088C

31. Taghavi S, HashemNia A, Mosaffa F, Askarian S, Abnous K, Ramezani M. Preparation and evaluation of polyethylenimine-functionalized carbon nanotubes tagged with 5TR1 aptamer for targeted delivery of Bcl-xL shRNA into breast cancer cells. Colloids Surf B. 2016;140:28-39. doi:10.1016/j. colsurfb.2015.12.021

32. Hernández-Rivera M, Zaibaq NG, Wilson LJ. Toward carbon nanotube-based imaging agents for the clinic. Biomaterials. 2016;101:229-240. doi:10.1016/j.biomaterials.2016.05.045

33. Wang Y, Liu J, Cui L, Losic D. Cytotoxicity, drug delivery, and photothermal therapy of functionalized carbon nanomaterials. In: Zhang M, Naik RR, Dai L, editors. Carbon Nanomaterials for Biomedical Applications. Cham: Springer International Publishing; 2016:81-111.

34. Budhathoki-Uprety J, Harvey JD, Isaac E, et al. Polymer cloaking modulates the carbon nanotube protein corona and delivery into cancer cells. J Mater Chem B. 2017;5:6637-6644. doi:10.1039/ C7TB00695K

35. Hassan HAFM, Smyth L, Rubio N, et al. Carbon nanotubes' surface chemistry determines their potency as vaccine nanocarriers in vitro and in vivo. $J$ Control Release. 2016;225:205-216. doi:10.1016/j.jconrel.2016.01.030
36. Ema M, Gamo M, Honda K. Regul. Toxicol Pharmacol. 2016;74:42-63.

37. Karimi M, Solati N, Amiri M, et al. Carbon nanotubes part I: preparation of a novel and versatile drug-delivery vehicle. Expert Opin Drug Deliv. 2015;12:1071-1087.

38. Son KH, Hong JH, Lee JW. Carbon nanotubes as cancer therapeutic carriers and mediators. Int $J$ Nanomed. 2016;11:5163-5185. doi:10.2147/IJN.S112660

39. Laura M, Franco T, Camillo La M, Adalberto B, Alberto B, Gianfranco R. Interactions and effects of BSA-functionalized single-walled carbon nanotubes on different cell lines. Nanotechnology. 2016;27:155704. doi:10.1088/0957-4484/27/15/155704

40. Al-Qattan MN, Deb PK, Tekade RK. Molecular dynamics simulation strategies for designing carbon-nanotube-based targeted drug delivery. Drug Discov Today. 2018;23:235-250. doi:10.1016/j.drudis.2017.10.002

41. Karimi M, Ghasemi A, Mirkiani S, Moosavi Basri SM, Hamblin MR. Carbon Nanotubes in Drug and Gene Delivery. Morgan \& Claypool Publishers; 2017:5-6.

42. Zhu S, Zhu B, Huang A, et al. Application of virus targeting nanocarrier drug delivery system in virus-induced central nervous system disease treatment. ACS Appl Mater Interfaces. 2016;318:650-662.

43. Caoduro C, Hervouet E, Girard-Thernier C, et al. Carbon nanotubes as gene carriers: focus on internalization pathways related to functionalization and properties. Acta Biomater. 2017;49:36-44. doi:10.1016/j.actbio.2016.11.013

44. Cui X, Xu S, Wang X, Chen C. The nano-bio interaction and biomedical applications of carbon nanomaterials. Carbon. 2018;138:436-450. doi:10.1016/j.carbon.2018.07.069

45. Parton RG, Collins BM. Unraveling the architecture of caveolae. Proc Natl Acad Sci. 2016;113:14170. doi:10.1073/pnas.1617954113

46. Li Z, de Barros ALB, Soares DCF, Moss SN, Alisaraie L. Functionalized single-walled carbon nanotubes: cellular uptake, biodistribution and applications in drug delivery. Int J Pharm. 2017;524:41-54. doi:10.1016/j.ijpharm.2017.03.017

47. Eldawud R, Wagner A, Dong C, Stueckle TA, Rojanasakul Y, Dinu CZ. Toxicity screening of two prevalent metal organic frameworks for therapeutic use in human lung epithelial cells. Nano Impact. 2018;9:72-84.

48. Xie L, Wang G, Zhou H, et al. Functional long circulating single walled carbon nanotubes for fluorescent/photoacoustic imaging-guided enhanced phototherapy. Biomaterials. 2016;103:219-228. doi:10.1016/j.biomaterials.2016.06.058

49. Eldridge BN, Xing F, Fahrenholtz CD, Singh RN. Evaluation of multiwalled carbon nanotube cytotoxicity in cultures of human brain microvascular endothelial cells grown on plastic or basement membrane. Toxicol in Vitro. 2017;41:223-231. doi:10.1016/ j.tiv.2017.03.002

50. Lacerda L, Russier J, Pastorin G, et al. Translocation mechanisms of chemically functionalised carbon nanotubes across plasma membranes. Biomaterials. 2012;33:3334-3343. doi:10.1016/j. biomaterials.2012.01.024

51. Bai W, Wu Z, Mitra S, Brown JM. Effects of multiwalled carbon nanotube surface modification and purification on bovine serum albumin binding and biological responses. $J$ Nanomater. 2016;2016:2159537. doi:10.1155/2016/2159537

52. Ursini CL, Maiello R, Ciervo A, et al. Evaluation of uptake, cytotoxicity and inflammatory effects in respiratory cells exposed to pristine and $-\mathrm{OH}$ and $-\mathrm{COOH}$ functionalized multi-wall carbon nanotubes. J Appl Toxicol. 2016;36:394 403. doi:10.1002/jat.3228

53. Chatterjee N, Yang J, Yoon D, Kim S, Joo S-W, Choi J. Differential crosstalk between global DNA methylation and metabolomics associated with cell type specific stress response by pristine and functionalized MWCNT. Biomaterials. 2017;115:167-180. doi:10.1016/j.biomaterials.2016.11.005 
54. Kafa H, Wang JT, Rubio N, et al. The interaction of carbon nanotubes with an in vitro blood-brain barrier model and mouse brain in vivo. Biomaterials. 2015;53:437-452. doi:10.1016/j. biomaterials.2015.02.083

55. Ren J, Shen S, Wang D, et al. The targeted delivery of anticancer drugs to brain glioma by PEGylated oxidized multi-walled carbon nanotubes modified with angiopep-2. Biomaterials. 2012;33:3324-3333. doi:10.1016/j.biomaterials.2012.01.025

56. Al-Jamal KT, Gherardini L, Bardi G, et al. Functional motor recovery from brain ischemic insult by carbon nanotube-mediated siRNA silencing. Proc Natl Acad Sci U S A. 2011;108:10952-10957. doi:10.1073/pnas.1100930108

57. Sciortino N, Fedeli S, Paoli P, et al. Multiwalled carbon nanotubes for drug delivery: efficiency related to length and incubation time. Int $J$ Pharm. 2017;521:69-72. doi:10.1016/j. ijpharm.2017.02.023

58. Jin S, Wijesekara P, Boyer PD, Dahl KN, Islam MF. Lengthdependent intracellular bundling of single-walled carbon nanotubes influences retention. J Mater Chem B. 2017;5:6657-6665. doi:10.1039/C7TB00735C

59. Shinde A, Tsai CSJ. Toxicity mechanism in fetal lung fibroblast cells for multi-walled carbon nanotubes defined by chemical impurities and dispersibility. Toxicol Res. 2016;5:248-258. doi:10.1039/C5TX00211G

60. Cui X, Wan B, Yang Y, Ren X, Guo L-H. Length effects on the dynamic process of cellular uptake and exocytosis of single-walled carbon nanotubes in murine macrophage cells. Sci Rep. 2017;7:1518. doi:10.1038/s41598-017-01746-9

61. Chatterjee N, Yang J, Kim S, Joo SW, Choi J. Diameter size and aspect ratio as critical determinants of uptake, stress response, global metabolomics and epigenetic alterations in multi-wall carbon nanotubes. Carbon. 2016;108:529-540. doi:10.1016/j. carbon.2016.07.031

62. Zhang M, Yang M, Morimoto T, et al. Size-dependent cell uptake of carbon nanotubes by macrophages: a comparative and quantitative study. Carbon. 2018;127:93-101. doi:10.1016/j.carbon.2017.10.085

63. Zhang M, Yang M, Okazaki T, Yudasaka M. Quantification of carbon nanotubes taken up by macrophage cells using optical absorption method. Surf Sci Nanotechnol. 2018;16:93-96. doi:10.1380/ejssnt.2018.93

64. Song Z-M, Wang L, Chen N, Cao A, Liu Y, Wang H. Biological effects of agglomerated multi-walled carbon nanotubes. Colloids Surf B. 2016;142:65-73. doi:10.1016/j.colsurfb.2016.02.032

65. Kuroda C, Ueda K, Haniu H, et al. Different aggregation and shape characteristics of carbon materials affect biological responses in RAW264 cells. Int $J$ Nanomed. 2018;13:6079-6088. doi:10.2147/IJN.S172493

66. Roxbury D, Jena PV, Shamay Y, Horoszko CP, Heller DA. Cell membrane proteins modulate the carbon nanotube optical bandgap via surface charge accumulation. ACS Nano. 2016;10:499-506. doi:10.1021/acsnano.5b05438

67. Taghavi S, Nia AH, Abnous K, Ramezani M. Polyethyleniminefunctionalized carbon nanotubes tagged with AS1411 aptamer for combination gene and drug delivery into human gastric cancer cells. Int J Pharm. 2017;516:301-312. doi:10.1016/j.ijpharm.2016.11.027

68. Summers HD, Rees P, Wang JTW, Al-Jamal KT. Spatiallyresolved profiling of carbon nanotube uptake across cell lines. Nanoscale. 2017;9:6800-6807. doi:10.1039/C7NR01561E

69. Jiang W, Wang Q, Qu X, et al. Effects of charge and surface defects of multi-walled carbon nanotubes on the disruption of model cell membranes. Sci Total Environ. 2017;574:771-780. doi:10.1016/j.scitotenv.2016.09.150

70. Cai X, Ramalingam R, Wong HS, et al. Characterization of carbon nanotube protein corona by using quantitative proteomics. Nanomedicine. 2013;9:583-593. doi:10.1016/j. nano.2012.09.004
71. Corbo C, Molinaro R, Parodi A, Toledano Furman NE, Salvatore F, Tasciotti E. The impact of nanoparticle protein corona on cytotoxicity, immunotoxicity and target drug delivery. Nanomedicine. 2015;11:81-100. doi:10.2217/nnm.15.188

72. Ge C, Du J, Zhao L, et al. Binding of blood proteins to carbon nanotubes reduces cytotoxicity. Proc Natl Acad Sci USA. 2011;108:16968-16973. doi:10.1073/pnas.1105270108

73. Elçin AE, Elçin AE, Elçin YM, Elçin YM. A comparative study on the in vitro cytotoxic responses of two mammalian cell types to fullerenes, carbon nanotubes and iron oxide nanoparticles. Drug Chem Toxicol. 2017;40:215-227. doi:10.1080/ 01480545.2016.1199563

74. Stan MS, Strugari AFG, Balas M, Nica IC. Chapter 2 - biomedical applications of carbon nanotubes with improved properties. In: Grumezescu AM, editor. Fullerenes, Graphenes and Nanotubes. William Andrew Publishing; 2018:31-65.

75. Karimi M, Solati N, Ghasemi A, et al. Temperature-responsive smart nanocarriers for delivery of therapeutic agents: applications and recent advances. Avci. 2015;12:1089-1105.

76. de Carvalho Lima EN, Piqueira JRC, Maria DA. Advances in carbon nanotubes for malignant melanoma: a chance for treatment. Mol Diag Ther. 2018;22:703-715. doi:10.1007/ s40291-018-0363-7

77. García-Hevia L, Villegas JC, Fernández F, et al. Multiwalled carbon nanotubes inhibit tumor progression in a mouse model. Adv Healthc Mater. 2016;5:1080-1087. doi:10.1002/adhm.201500753

78. Hopkins S, Gottipati MK, Montana V, Bekyarova E, Haddon RC, Parpura V. Leveraging science to advance health equity: a regional health policy research center's approach. Neurol. 2018;1:327-338.

79. Judge A, McClintock K, Phelps JR, Maclachlan I. Hypersensitivity and loss of disease site targeting caused by antibody responses to PEGylated liposomes. Mol Ther. 2006;13:328-337. doi:10.1016/j.ymthe.2005.09.014

80. Sroda K, Rydlewski J, Langner M, Kozubek A, Grzybek M, Sikorski AF. Repeated injections of PEG-PE liposomes generate anti-PEG antibodies.. Cell Mol Biol Lett. 2005;10:37-47.

81. Dams ET, Laverman P, Oyen WJ, et al. Accelerated blood clearance and altered biodistribution of repeated injections of sterically stabilized liposomes. $J$ Pharmacol Exp Ther. 2000;292:1071-1079.

82. Macdougall IC, Provenzano R, Sharma A, et al. Peginesatide for anemia in patients with chronic kidney disease not receiving dialysis. $N$ Engl J Med. 2013;368:320-332. doi:10.1056/ NEJMoa1203166

83. Eckardt KU. The safety and efficacy of peginesatide in patients with CKD. Nat Rev Nephrol. 2013;9:192-193. doi:10.1038/ nrneph.2013.42

84. Elsadek NE, Abu Lila AS, Ishida T. 5 - immunological responses to PEGylated proteins: anti-PEG antibodies. In: Pasut G, Zalipsky S, editors. Polymer-Protein Conjugates. Elsevier; 2020:103-123.

85. Eldridge BN, Bernish BW, Fahrenholtz CD, Singh R. Photothermal therapy of glioblastoma multiforme using multiwalled carbon nanotubes optimized for diffusion in extracellular space. ACS Biomater Sci Eng. 2016;2:963-976. doi:10.1021/ acsbiomaterials.6b00052

86. Li B, Zhang XX, Huang HY, et al. Effective deactivation of A549 tumor cells in vitro and in vivo by RGD-decorated chitosan-functionalized single-walled carbon nanotube loading docetaxel. Int $J$ Pharm. 2018;543:8-20. doi:10.1016/j. ijpharm.2018.03.017

87. Kim SW, Kyung Lee Y, Yeon Lee J, Hee Hong J, Khang D. PEGylated anticancer-carbon nanotubes complex targeting mitochondria of lung cancer cells. Nanotechnology. 2017;28:465102. doi:10.1088/1361-6528/aa8c31 
88. Weis SM, Cheresh DA. Integrins in angiogenesis and cancer. Cold Spring Harb Perspect Med. 2011;1:a006478. doi:10.1101/ cshperspect.a006478

89. Koh B, Park SB, Yoon E, et al. $\alpha$ V $\beta 3$-targeted delivery of camptothecin-encapsulated carbon nanotube-cyclic RGD in 2D and 3D cancer cell culture. J Pharm Sci. 2019;108:3704-3712. doi:10.1016/j.xphs.2019.07.011

90. Liu X, Xu D, Liao C, Fang Y, Guo B. Development of a promising drug delivery for formononetin: cyclodextrin-modified single-walled carbon nanotubes. J Drug Deliv Sci Tech. 2018;43:461-468. doi:10.1016/j. jddst.2017.11.018

91. Wauthoz N, Balde A, Balde ES, Van Damme M, Duez P. Ethnopharmacology of Mangifera indica L. bark and pharmacological studies of its main C-glucosylxanthone, mangiferin. Int J Biomed Pharm Sci. 2007;1:112-119.

92. Harsha P, Thotakura N, Kumar M, et al. A novel PEGylated carbon nanotube conjugated mangiferin: an explorative nanomedicine for brain cancer cells. J Drug Deliv Sci Technol. 2019;53:101186. doi:10.1016/j.jddst.2019.101186

93. Raza K, Kumar D, Kiran C, et al. Conjugation of docetaxel with multiwalled carbon nanotubes and codelivery with piperine: implications on pharmacokinetic profile and anticancer activity. Mol Pharm. 2016;13:2423-2432. doi:10.1021/acs.molpharma ceut.6b00183

94. Razzazan A, Atyabi F, Kazemi B, Dinarvand R. In vivo drug delivery of gemcitabine with PEGylated single-walled carbon nanotubes. Mater Sci Eng C Mater. 2016;62:614-625. doi:10.1016/j.msec.2016.01.076

95. Pugazhendhi A, Edison T, Velmurugan BK, Jacob JA, Karuppusamy I. Toxicity of doxorubicin (Dox) to different experimental organ systems. Life Sci. 2018;200:26-30. doi:10.1016/j.lfs.2018.03.023

96. He H, Pham-Huy LA, Dramou P, Xiao D, Zuo P, Pham-Huy C. Carbon nanotubes: applications in pharmacy and medicine. Biomed Res Int. 2013;2013:578290. doi:10.1155/2013/578290

97. Liu D, Zhang Q, Wang J, Fan L, Zhu W, Cai D. Hyaluronic acid-coated single-walled carbon nanotubes loaded with doxorubicin for the treatment of breast cancer. Pharmazie. 2019;74:83-90. doi:10.1691/ph.2019.8152

98. Liu D, Zhang Q, Wang J, Fan L, Zhu W, Cai D. Hyaluronic acid-coated single-walled carbon nanotubes loaded with doxorubicin for the treatment of breast cancer. Die Pharmazie. 2019;74:83-90

99. Yan Y, Wang R, Hu Y, et al. Stacking of doxorubicin on folic acid-targeted multiwalled carbon nanotubes for in vivo chemotherapy of tumors. Drug Deliv. 2018;25:1607-1616. doi:10.1080/10717544.2018.1501120

100. Uttekar PS, Lakade SH, Beldar VK, Harde MT. Facile synthesis of multi-walled carbon nanotube via folic acid grafted nanoparticle for precise delivery of doxorubicin. IET Nanobiotechnol. 2019;13:688-696. doi:10.1049/iet-nbt.2018.5421

101. Yu B, Tan L, Zheng R, Tan H, Zheng L. Targeted delivery and controlled release of Paclitaxel for the treatment of lung cancer using single-walled carbon nanotubes. Mater Sci Eng C Mater Biol Appl. 2016;68:579-584. doi:10.1016/j.msec.2016.06.025

102. Karnati KR, Wang Y. Understanding the co-loading and releasing of doxorubicin and paclitaxel using chitosan functionalized single-walled carbon nanotubes by molecular dynamics simulations. Phys Chem. 2018;20:9389-9400.

103. Saeednia L, Yao L, Cluff K, Asmatulu R. Sustained releasing of methotrexate from injectable and thermosensitive chitosan-carbon nanotube hybrid hydrogels effectively controls tumor cell growth. ACS Omega. 2019;4:4040-4048. doi:10.1021/ acsomega.8b03212
104. Karimi M, Solati N, Amiri M, et al. Carbon nanotubes part I: preparation of a novel and versatile drug-delivery vehicle. Expert Opin Drug Deliv. 2015;12:1071-1087.

105. Behnam MA, Emami F, Sobhani Z, et al. Novel combination of silver nanoparticles and carbon nanotubes for plasmonic photo thermal therapy in melanoma cancer model. Adv Pharm Bull. 2018;8:49-55. doi:10.15171/apb.2018.006

106. Sobhani Z, Behnam MA, Emami F, Dehghanian A, Jamhiri I. Photothermal therapy of melanoma tumor using multiwalled carbon nanotubes. Int J Nanomed. 2017;12:4509-4517. doi:10.2147/ IJN.S134661

107. Wang R, Xiao R, Zeng Z, Xu L, Wang J. Application of poly (ethylene glycol)-distearoylphosphatidylethanolamine (PEGDSPE) block copolymers and their derivatives as nanomaterials in drug delivery. Int J Nanomed. 2012;7:4185-4198.

108. Kitiyanan B, Alvarez W, Harwell J, Resasco D. Controlled production of single-wall carbon nanotubes by catalytic decomposition of $\mathrm{CO}$ on bimetallic Co-Mo catalysts. Chem Phys Lett. 2000;317:497-503. doi:10.1016/S0009-2614(99)01379-2

109. Li Y, Li X, Doughty A, et al. Phototherapy using immunologically modified carbon nanotubes to potentiate checkpoint blockade for metastatic breast cancer. Nanomed. 2019;18:44-53. doi:10.1016/j.nano.2019.02.009

110. Virani NA, Davis C, McKernan P, et al. Phosphatidylserine targeted single-walled carbon nanotubes for photothermal ablation of bladder cancer. Nanotechnol. 2018;29:035101. doi:10.1088/ 1361-6528/aa9c0c

111. Han S, Kwon T, Um JE, Haam S, Kim WJ. Highly selective photothermal therapy by a phenoxylated-dextran-functionalized smart carbon nanotube platform. Adv Healthc Mater. 2016;5:1147-1156. doi:10.1002/adhm.201600015

112. Castano AP, Mroz P, Hamblin MR. Photodynamic therapy and anti-tumour immunity. Nat Rev Cancer. 2006;6:535-545. doi:10.1038/nrc1894

113. Zhang M, Wang W, Cui Y, et al. Magnetofluorescent Fe3O4/ carbon quantum dots coated single-walled carbon nanotubes as dual-modal targeted imaging and chemo/photodynamic/photothermal triple-modal therapeutic agents. Chem Eng J. 2018;338:526-538. doi:10.1016/j.cej.2018.01.081

114. Hou L, Yang X, Ren J, et al. A novel redox-sensitive system based on single-walled carbon nanotubes for chemo-photothermal therapy and magnetic resonance imaging. Int $J$ Nanomed. 2016;11:607-624.

115. Hasan M, Campbell E, Sizova O, et al. Multi-drug/gene NASH therapy delivery and selective hyperspectral NIR imaging using chirality-sorted single-walled carbon nanotubes. Cancers. 2019;11:1175. doi:10.3390/cancers 11081175

116. Arosio P, Comito G, Orsini F, et al. Conjugation of a GM3 lactone mimetic on carbon nanotubes enhances the related inhibition of melanoma-associated metastatic events. Org Biomol. 2018;16:6086-6095. doi:10.1039/C8OB01817K

117. Dong Z, Wang Q, Huo M, et al. Mannose-modified multi-walled carbon nanotubes as a delivery nanovector optimizing the antigen presentation of dendritic cells. Chem Open. 2019;8:915-921. doi:10.1002/open.201900126

118. Zhang B, Wang H, Shen S, et al. Fibrin-targeting peptide CREKA-conjugated multi-walled carbon nanotubes for self-amplified photothermal therapy of tumor. Biomaterials. 2016;79:46-55. doi:10.1016/j.biomaterials.2015.11.061

119. Da Ros T, Ostric A, Andreola F, et al. Carbon nanotubes as nanovectors for intracellular delivery of laronidase in Mucopolysaccharidosis type I. Nanoscale. 2018;10:657-665. doi:10.1039/C7NR07393C

120. Golshadi M, Wright LK, Dickerson IM, Schrlau MG. Highefficiency gene transfection of cells through carbon nanotube arrays. Small. 2016;12:3014-3020. doi:10.1002/smll.201503878 
121. Cao Y, Huang H-Y, Chen L-Q, et al. Enhanced lysosomal escape of $\mathrm{pH}$-responsive polyethylenimine-betaine functionalized carbon nanotube for the codelivery of survivin small interfering RNA and doxorubicin. ACS Appl Mater Interfaces. 2019;11:9763-9776. doi:10.1021/acsami.8b20810

122. Demirer GS, Zhang H, Goh NS, Pinals RL, Chang R, Landry MP. Nanobiolistics: an emerging genetic transformation approach. bioRxiv. 2019;564427.

123. Kwak S-Y, Lew TTS, Sweeney CJ, et al. Chloroplast-selective gene delivery and expression in planta using chitosan-complexed single-walled carbon nanotube carriers. Nat Nanotechnol. 2019;14:447-455. doi:10.1038/s41565-019-0375-4

124. Ren X, Lin J, Wang X, et al. Photoactivatable RNAi for cancer gene therapy triggered by near-infrared-irradiated single-walled carbon nanotubes. Int $J$ Nanomed. 2017;12:7885-7896. doi:10.2147/IJN.S141882

125. Pantarotto D, Singh R, McCarthy D, et al. Functionalized carbon nanotubes for plasmid DNA gene delivery. Angew Chem Int Ed Engl. 2004;43:5242-5246. doi:10.1002/anie.200460437

126. Hu F, Li Y, Wang Q, et al. Carbon nanotube-based DNA vaccine against koi herpesvirus given by intramuscular injection. Fish Shellfish Immunol. 2020;98:810-818. doi:10.1016/j.fsi.201 9.11.035

127. Hashem Nia A, Behnam B, Taghavi S, et al. Evaluation of chemical modification effects on DNA plasmid transfection efficiency of single-walled carbon nanotube-succinate- polyethylenimine conjugates as non-viral gene carriers. Med Chem Comm. 2016;8:364-375. doi:10.1039/C6MD00481D

128. Munk M, de Souza Salomão R, Zanette LS, et al. Using carbon nanotubes to deliver genes to hard-to-transfect mammalian primary fibroblast cells. Biomed Phys Eng Express. 2017;3:045002. doi:10.1088/2057-1976/aa7927

129. Munk M, Ladeira LO, Carvalho BC, et al. Efficient delivery of DNA into bovine preimplantation embryos by multiwall carbon nanotubes. Sci Rep. 2016;6:33588. doi:10.1038/srep33588

130. Ghasemi A, Amiri H, Zare H, et al. Carbon nanotubes in microfluidic lab-on-a-chip technology: current trends and future perspectives. Microfluid Nanofluid. 2017;21.

131. Sukhodub LB, Sukhodub LF, Prylutskyy YI, et al. Composite material based on hydroxyapatite and multi-walled carbon nanotubes filled by iron: preparation, properties and drug release ability. Mater Sci Eng C. 2018;93:606-614. doi:10.1016/j. msec.2018.08.019

132. Havaldar R, Pilli SC, Putti BB. Insights into the effects of tensile and compressive loadings on human femur bone. Adv Biomed Res. 2014;3:101. doi:10.4103/2277-9175.129375

133. Moon SU, Kim J, Bokara KK, et al. Carbon nanotubes impregnated with subventricular zone neural progenitor cells promotes recovery from stroke. Int J Nanomed. 2012;7:2751-2765.

134. Sirivisoot S, Pareta R, Webster TJ. Electrically controlled drug release from nanostructured polypyrrole coated on titanium. Nanotechnol. 2011;22:085101. doi:10.1088/0957-4484/22/8/ 085101

135. Serra M, Arenal R, Tenne R. An overview of the recent advances in inorganic nanotubes. Nanoscale. 2019;11:8073-8090. doi:10.1039/C9NR01880H

136. Arbulu RC, Jiang YB, Peterson EJ, Qin Y. Metal-Organic Framework (MOF) nanorods, nanotubes, and nanowires. Angew Chem Int. 2018;57:5813-5817. doi:10.1002/anie.201802694

137. Wei Y-S, Zhang M, Kitta M, Liu Z, Horike S, Xu Q. A singlecrystal open-capsule Metal-Organic Framework. J Am Chem Soc. 2019;141:7906-7916. doi:10.1021/jacs.9b02417

138. Huang J, Zhang X, Yan W, et al. Nanotubular topography enhances the bioactivity of titanium implants. Nanomed. 2017;13:1913-1923. doi:10.1016/j.nano.2017.03.017
139. Tharmavaram M, Pandey G, Rawtani D. Surface modified halloysite nanotubes: a flexible interface for biological, environmental and catalytic applications. Adv Colloid Interface Sci. 2018;261:82-101. doi:10.1016/j.cis.2018.09.001

140. Barman M, Mahmood S, Augustine R, Hasan A, Thomas S, Ghosal K. Natural halloysite nanotubes/chitosan based bio-nanocomposite for delivering norfloxacin, an anti-microbial agent in sustained release manner. Int $J$ Biol Macromol. 2020;162:1849-1861. doi:10.1016/j.ijbiomac.2020.08.060

141. Tîlmaciu C-M, Morris MC. Carbon nanotube biosensors. Front Chem. 2015;3:59. doi:10.3389/fchem.2015.00059

142. Palmer BC, Phelan-Dickenson SJ, DeLouise LA. Multi-walled carbon nanotube oxidation dependent keratinocyte cytotoxicity and skin inflammation. Part Fibre Toxicol. 2019;16:3. doi:10.1186/s12989-018-0285-x

143. Dong J, Ma Q. Type 2 immune mechanisms in carbon nanotube-induced lung fibrosis. Front Immunol. 2018;9.

144. Bai Y, Zhang Y, Zhang J, et al. Repeated administrations of carbon nanotubes in male mice cause reversible testis damage without affecting fertility. Nat Nanotechnol. 2010;5:683-689. doi:10.1038/nnano.2010.153

145. Costa PM, Wang JT-W, Morfin J-F, et al. Functionalised carbon nanotubes enhance brain delivery of amyloid-targeting Pittsburgh compound B (PiB)-derived ligands. Nanotheranostics. 2018;2:168-183. doi:10.7150/ntno.23125

146. Long J, Xiao Y, Liu L, Cao Y. The adverse vascular effects of multi-walled carbon nanotubes (MWCNTs) to human vein endothelial cells (HUVECs) in vitro: role of length of MWCNTs. J Nanobiotechnology. 2017;15:80. doi:10.1186/ s12951-017-0318-x

147. de Eguileor M, de Eguileor M, de Eguileor M, et al. Systemic distribution of single-walled carbon nanotubes in a novel model: alteration of biochemical parameters, metabolic functions, liver accumulation, and inflammation in vivo. Int $J$ Nanomed. 2016;11:4299-4316. doi:10.2147/IJN.S109950

148. Sun X, Shao H, Xiang K, et al. Poly(dopamine)-modified carbon nanotube multilayered film and its effects on macrophages. Carbon. 2017;113:176-191. doi:10.1016/j.carbon.2016.11.040

149. Perepelytsina OM, Ugnivenko AP, Dobrydnev AV, Bakalinska ON, Marynin AI, Sydorenko MV. Influence of carbon nanotubes and its derivatives on tumor cells in vitro and biochemical parameters, cellular blood composition in vivo. Nanoscale Res Lett. 2018;13:286. doi:10.1186/s11671-018-2689-9

150. Dayani Y, Malmstadt N. Lipid bilayers covalently anchored to carbon nanotubes. Langmuir. 2012;28:8174-8182. doi:10.1021/ la301094h

151. Hong G, Diao S, Antaris AL, Dai H. Carbon nanomaterials for biological imaging and nanomedicinal therapy. Chem Rev. 2015;115:10816-10906.

152. Singh R, Torti SV. Carbon nanotubes in hyperthermia therapy. Adv Drug Deliv Rev. 2013;65:2045-2060. doi:10.1016/j. addr.2013.08.001

153. Harrison BS, Atala A. Carbon nanotube applications for tissue engineering. Biomaterials. 2007;28:344-353. doi:10.1016/j. biomaterials.2006.07.044

154. Bianco A, Kostarelos K, Prato M. Applications of carbon nanotubes in drug delivery. Curr Opin Chem Biol. 2005;9:674-679. doi:10.1016/j.cbpa.2005.10.005

155. Ghasemi A, Amiri H, Zare H, et al. Carbon nanotubes in microfluidic lab-on-a-chip technology: current trends and future perspectives. Microfluid Nanofluidics. 2017;21:151.

156. Cherukuri P, Bachilo SM, Litovsky SH, Weisman RB, Am J. Near-infrared fluorescence microscopy of single-walled carbon nanotubes in phagocytic cells. Chem Soc. 2004;126:15638-15639. doi:10.1021/ja0466311 
157. Zhang X, Meng L, Wang X, Lu Q. Preparation and cellular uptake of $\mathrm{pH}$-dependent fluorescent single-wall carbon nanotubes. Chemistry. 2010;16:556-561. doi:10.1002/ chem. 200901168

158. Haniu H, Saito N, Matsuda Y, et al. Culture medium type affects endocytosis of multi-walled carbon nanotubes in BEAS-2B cells and subsequent biological response. Toxicol in Vitro. 2013;27:1679-1685. doi:10.1016/j.tiv.2013.04.012

159. Kam NWS, Liu Z, Dai H. Carbon nanotubes as intracellular transporters for proteins and DNA: an investigation of the uptake mechanism and pathway. Angew Chem Int Ed. 2006;45:577-581. doi:10.1002/anie.200503389

160. Song S, Fu H, He B, et al. Rho GTPases in A549 and Caco-2 cells dominating the endocytic pathways of nanocarbons with different morphologies. Int J Nanomed. 2018;13:4391-4404. doi:10.2147/IJN.S164866

161. Kang B, Yu DC, Chang SQ, Chen D, Dai YD, Ding Y. Intracellular uptake, trafficking and subcellular distribution of folate conjugated single walled carbon nanotubes within living cells. Nanotechnology. 2008;19:375103. doi:10.1088/0957-4484/ 19/37/375103

162. Kang B, Yu D, Dai Y, Chang S, Chen D, Ding Y. Cancer-cell targeting and photoacoustic therapy using carbon nanotubes as "bomb" agents. Small. 2009;5:1292-1301. doi:10.1002/ smll.200801820

163. Zhang LW, Monteiro-Riviere NA. Lectins modulate multi-walled carbon nanotubes cellular uptake in human epidermal keratinocytes. Toxicol in Vitro. 2010;24:546-551. doi:10.1016/j.tiv.2009.11.007

164. Kang B, Chang S, Dai Y, Yu D, Chen D. Cell response to carbon nanotubes: size-dependent intracellular uptake mechanism and subcellular fate. Small. 2010;6:2362-2366. doi:10.1002/ smll.201001260

165. Serag MF, Kaji N, Gaillard C, et al. Trafficking and subcellular localization of multiwalled carbon nanotubes in plant cells. $A C S$ Nano. 2011;5:493-499. doi:10.1021/nn102344t

166. Zhou F, Xing D, Wu B, Wu S, Ou Z, Chen WR. New insights of transmembranal mechanism and subcellular localization of noncovalently modified single-walled carbon nanotubes. Nano Lett 2010;10:1677-1681. doi:10.1021/nl100004m

167. Manzanares D, Ceña V. Endocytosis: the nanoparticle and submicron nanocompounds gateway into the cell. Pharmaceutics. 2020;12:371. doi:10.3390/pharmaceutics12040371

168. Rejman J, Oberle V, Zuhorn IS, Hoekstra D. Size-dependent internalization of particles via the pathways of clathrin- and caveolae-mediated endocytosis. Biochem J. 2004;377:159-169. doi:10.1042/bj20031253

169. Rappaport J, Manthe RL, Solomon M, Garnacho C, Muro S. A comparative study on the alterations of endocytic pathways in multiple lysosomal storage disorders. Mol Pharm. 2016;13:357-368. doi:10.1021/acs.molpharmaceut.5b00542

170. Zhang H, Li HX, Cheng HM. Water-soluble multiwalled carbon nanotubes functionalized with sulfonated polyaniline. $J$ Phys Chem B. 2006;110:9095-9099. doi:10.1021/jp060193y

171. Hadidi N, Hosseini Shirazi SF, Kobarfard F, Nafissi-Varchehd N, Aboofazeli R. Evaluation of the effect of PEGylated single-walled carbon nanotubes on viability and proliferation of jurkat cells. Iran J Pharm Res. 2012;11:27-37.
172. Ketabi S, Rahmani L. Carbon nanotube as a carrier in drug delivery system for carnosine dipeptide: a computer simulation study. Mater Sci Eng. 2017;73:173-181. doi:10.1016/j. msec.2016.12.058

173. Farvadi F, Tamaddon A, Sobhani Z, Abolmaali SS. Polyionic complex of single-walled carbon nanotubes and PEG-graftedhyperbranched polyethyleneimine (PEG-PEI-SWNT) for an improved doxorubicin loading and delivery: development and in vitro characterization. Artif Cells Nanomed Biotechnol. 2017;45(5):855-863. doi:10.1080/21691401.2016.1181642

174. Dong X, Sun Z, Wang X, Zhu D, Liu L, Leng X. Simultaneous monitoring of the drug release and antitumor effect of a novel drug delivery system-MWCNTs/DOX/TC. Drug Deliv. 2017;24:143-151. doi:10.1080/10717544.2016.1233592

175. Hossein Panahi F, Peighambardoust SJ, Davaran S, Salehi R. Development and characterization of PLA-mPEG copolymer containing iron nanoparticle-coated carbon nanotubes for controlled delivery of Docetaxel. Polymer. 2017;117:117-131. doi:10.1016/ j.polymer.2017.03.084

176. Li H, Fan X, Chen X. Near-infrared light activation of proteins inside living cells enabled by carbon nanotube-mediated intracellular delivery. ACS Appl Mater Interfaces. 2016;8:4500-4507. doi:10.1021/acsami.6b00323

177. Mallakpour S, Khodadadzadeh L. Ultrasonic-assisted fabrication of starch/MWCNT-glucose nanocomposites for drug delivery. Ultrason Sonochem. 2018;40:402-409. doi:10.1016/j. ultsonch.2017.07.033

178. Oh Y, Jin JO, Oh J. Photothermal-triggered control of sub-cellular drug accumulation using doxorubicin-loaded single-walled carbon nanotubes for the effective killing of human breast cancer cells. Nanotechnology. 2017;28:1361-6528. doi:10.1088/1361$6528 / \mathrm{aa} 5 \mathrm{~d} 7 \mathrm{~d}$

179. Singh RP, Sharma G, Koch B, Pandey BL, Koch B, Muthu MS. Chitosan-folate decorated carbon nanotubes for site specific lung cancer delivery. Mater Sci Eng C Mater. 2017;77:446-458. doi:10.1016/j.msec.2017.03.225

180. Xing J, Liu Z, Huang Y, et al. Lentinan-modified carbon nanotubes as an antigen delivery system modulate immune response in vitro and in vivo. ACS Appl Mater Interfaces. 2016;8:19276-19283. doi:10.1021/acsami.6b04591

181. Chowdhry A, Kaur J, Khatri M, Puri V, Tuli R, Puri S. Characterization of functionalized multiwalled carbon nanotubes and comparison of their cellular toxicity between HEK 293 cells and zebra fish in vivo. Heliyon. 2019;5:e02605. doi:10.1016/j. heliyon.2019.e02605

182. Sato Y, Yokoyama A, Nodasaka Y, et al. Long-term biopersistence of tangled oxidized carbon nanotubes inside and outside macrophages in rat subcutaneous tissue. Sci Rep. 2013;3:2516. doi: $10.1038 /$ srep02516

183. Schipper ML, Nakayama-Ratchford N, Davis CR, et al. A pilot toxicology study of single-walled carbon nanotubes in a small sample of mice. Nat Nanotechnol. 2008;3:216-221. doi:10.1038/ nnano. 2008.68 


\section{Publish your work in this journal}

The International Journal of Nanomedicine is an international, peerreviewed journal focusing on the application of nanotechnology in diagnostics, therapeutics, and drug delivery systems throughout the biomedical field. This journal is indexed on PubMed Central, MedLine, CAS, SciSearch ${ }^{\circledR}$, Current Contents ${ }^{\circledR} /$ Clinical Medicine,
Journal Citation Reports/Science Edition, EMBase, Scopus and the Elsevier Bibliographic databases. The manuscript management system is completely online and includes a very quick and fair peer-review system, which is all easy to use. Visit http://www.dovepress.com/ testimonials.php to read real quotes from published authors. 